\title{
Numerical simulation of large dunes in meandering streams and rivers with in-stream rock structures
}

\author{
Ali Khosronejad ${ }^{\mathrm{a}}$, Jessica L. Kozarek ${ }^{\mathrm{a}}$, Margaret L. Palmsten ${ }^{\mathrm{b}}$, Fotis Sotiropoulos*a \\ ${ }^{a}$ Saint Anthony Falls Laboratory, University of Minnesota, 2 Third Ave. SE, Minneapolis, Minnesota, \\ USA, *Corresponding author, Eamil: fotis@umn.edu \\ ${ }^{b}$ National Research Council Post-doctoral Fellow, Naval Research Laboratory, Stennis Space Center, \\ Mississippi, USA
}

\begin{abstract}
The evolution and migration of large dunes in a realistic intermediate-size experimental stream, the Saint Anthony Falls Laboratory (SAFL) Outdoor StreamLab (OSL), and two large-scale meandering rivers with in-stream rock structures are studied numerically using the SAFL Virtual StreamLab hydro-morphodynamic (VSL3D) model. Due to the challenges arising from mesh quality and large disparity in time-scales, coupled morphoand hydro-dynamics simulations of bed forms has, for the most part, been restricted to sand wave amplitudes of few centimeters. In this work, we overcome such difficulties by employing the immersed boundary approach and a dual time-stepping technique of the VSL3D model [63]. The VSL3D employs the curvilinear immersed boundary (CURVIB) method along with a suspended sediment load module and is capable of simulating turbulent stratified flows coupled with bed morphodynamic evolution in realistic riverine environments with arbitrarily complex hydraulic structures. Turbulence is handled either via large-eddy simulation (LES) with the dynamic Smagorinski subgrid scale model or unsteady Reynolds-averaged Navier Stokes (URANS) equations closed with the $k-\omega$ turbulence model. Simulations in the intermediate-scale OSL channel, in which we also collected experimental morphodynamic data, show that LES can capture the evolution and migration of bed forms with characteristics that are in good agreement with experimental measurements. The URANS model, however, fails to excite the bed instability in the OSL channel but captures realistic dune evolution in the two large-scale meandering rivers. This finding is especially important as it demonstrates the potential of the VSL3D model as a powerful tool for simulating morphodynamic evolution under prototype conditions. To our knowledge, our work is the first attempt to simulate large-scale bed forms in waterways with an order of magnitude disparity in spatial scales, from the $\sim 2.7 \mathrm{~m}$ wide OSL channel to the $27 \mathrm{~m}$ wide rivers. Accordingly, the height of the simulated dunes ranges from $\sim 0.2 \mathrm{~m}$ to $2.0 \mathrm{~m}$ and the wavelength ranges from $\sim 0.1 \mathrm{~m}$ to $50 \mathrm{~m}$ for the OSL and large-scale rivers, respectively. For all cases the statistical properties of the simulated bed forms are shown to agree well with those of bed forms observed in nature.
\end{abstract}

Keywords: LES; URANS; bed form; Dune; Numerical simulation 


\section{Introduction}

Continuous transport of bed material in natural waterways caused by turbulent flow can lead to the formation, growth, and migration of multi-scale bed forms. Once turbulence gives rise to the formation of bed forms they rearrange the geometry of a mobile-bed and ultimately influence the turbulent flow in many ways including creating a wake zone downstream of the wave crest, shedding of vortices over the crestline, and rearranging the near bed high and low shear zones [64]. The study of bed form dynamics can help to obtain insights into the response of riverine systems to different flow fields and flooding events. Dune migration in field-scale rivers can temporarily cause deep holes at dune troughs while an increase in bed elevation is also expected to happen near dune crestlines. Thus, when it comes to the prediction of scour hole depth in riverine systems (often under live-bed conditions) it is important to have insights into the amplitude, wavelength, and geometry of bed forms passing through the system. Its also important to note that bed forms dynamics can also significantly affect the ecology of the waterways $[71,10,11,1]$.

Because of the importance of fluvial sediment transport mechanisms, numerous papers have been devoted to the study of bed form dynamics. These studies range from experimental/analytical to numerical investigations. The majority of studies aim to predict bed form shape and size in various river geometries and flow conditions. The simplest models are those that employ linear stability theory and are appropriate for describing very small scale bed forms with amplitude $(\Delta)$ of less than $1.0 \mathrm{~cm}$ (e.g. see $[58,44,48,39,81,23,29,27,28])$.

Computational studies investigating turbulent flow over artificially frozen bed form geometries seek to investigate the dynamics of coherent vortical structures and the effect of waveform geometry on turbulence in the absence of interactive coupling between the two. Such studies include, among others, the works of Blondeaux and Vittori [8], Scandura et al. [86], Barr et al. [6], Chang and Scotti [13], Best [7], Zedler and Street [101, 102], Henn and Sykes [45], Chang and Scotti [14], Zou et al. [103], Yue et al. [100], Angelis et al. [3], and Chau and Bhaganagar [16]. Only a few works are devoted to simulating coupled flow and bed morphodynamics, resolving turbulent flow induced sediment transport mechanisms and the interaction between them. Chou and Fringer [18] employed an Arbitrary Lagrangian-Eulerian (ALE) method along with a LES model to simulate small-scale ripples $(O(\leq 2 \mathrm{~cm}))$ induced by oscillatory waves. Escauriaza and Sotiropoulos [37] employed the ALE technique with the Detached Eddy Simulation (DES) method to simulate turbulent flow and morphodynamics of sand waves during their initial stages $(O(\leq 1 \mathrm{~cm}))$. In a recent work, Nabi et al. [74] employed a LES-based coupled hydro- and morphodynamic model to simulate the sand wave development in a $1.5 \mathrm{~m}$ wide rectangular laboratory flume. They also systematically investigated the effect of sediment particle size on the geometrical shape of the numerically captured sand waves (less than $8 \mathrm{~cm}$ high). More recently, Khosronejad and Sotiropoulos [64] simulated the coupled stratified flow and bed morphodynamics of sand wave development in an laboratory flume that was experimentally observed by Venditti et al. [95]. They employed the curvilinear immersed boundary method of Khosronejad et al. [60] and showed that the initiation of sand waves is linked to the characteristics of turbulent flow over the flat bed.

${ }_{45}$ They also showed that the qualitative and quantitative characteristics of the simulated 46 bed forms, whose amplitude was of the order of $\sim 5 \mathrm{~cm}$, were in good agreement with the 
experimental measurements.

As follows from the above literature review, past attempts to simulate numerically sand wave dynamics have been restricted to reproduce small-scale bed forms with amplitudes not exceeding few centimeters $[15,84,91,37,18,75,65]$. There are two major difficulties limiting the applicability of most numerical models to small-scale bed forms:

(i) Most methods employ the ALE approach, which requires that the grid conforms to the boundary shape at all times. This requirement restricts the application of such methods to simulations of small amplitude bed forms for which the mesh deformation remains small at all times (for more details see [64]); and (ii) The time scale for the sediment transport process is about two orders of magnitude greater than that of the instantaneous turbulent flow field [73]. Given this different in time scale, the coupled simulation of large-scale bed form evolution, which could take up to months of physical time, can be extremely expensive regardless of the underlying numerical approach. In order to overcome these problems and simulate the development of large-scale bed forms we employ in this work the VSL3D model, which has the following capabilities: $(i)$ It employs the CURVIB method to handle arbitrarily large deformations on the mobile bed. In the CURVIB framework we use two different grid systems: one structured background grid system for the flow field computations, and one unstructured grid system for discretizing and tracking the motion of the and sediment/water interface layer. The unstructured grid of the mobile bed can freely deform without influencing the quality of the background grid; and (ii) It features a dual time-stepping quasi-synchronization method (for more details see [63]) for decoupling the hydrodynamic and morphodynamic time-steps, which is essential for simulating cases requiring long period of physical time to reach equilibrium state (e.g. the large-scale bed form evolution in large rivers that could take up to a months to reach equilibrium). The VSL3D also incorporates both LES and URANS turbulence modeling strategies [54, 55].

The capabilities of the VSL3D to carry out high-fidelity LES of the coupled co-evolution of the flow and sand waves in a straight laboratory flume was recently demonstrated by Khosronejad and Sotiropoulos [64]. In this study the VSL3D was applied to a case studied experimentally by Venditti et al. [94] using very fine computational grids (up to 90 million grid nodes) and fully synchronized hydro-morphodynamic simulation. It was shown that the model is able to capture the observed in the laboratory initiation, growth and migration of sand waves with very good qualitative and quantitative accuracy. More specifically, the computed temporal evolution of sand wave amplitude, celerity, wave length and degree of three-dimensionality were shown to be in excellent agreement with the data of Venditii et al. [94]. The computed results were further analyzed to elucidate the role of near-bed sweeps in de-stabilizing the initially flat bed, clarify the process via which bed forms migrate, and further elucidate the mechanisms via which horseshoeshaped coherent structures induced by the migrating bed-forms grow and affect the flow at the free-surface. The work of Khosronejad and Sotiropoulos also provided new insights into the statistical properties of sand waves and their distinct signature into the flow velocity spectra as function of distance from the bed [64]. It should be noted, however, that all simulations reported in [64] were carried out for a straight, laboratory-scale flume with bed form amplitudes not exceeding $\sim 6 \mathrm{~cm}$.

In this paper we seek to demonstrate for the first time that the VSL3D model can be a powerful hydraulic engineering computational tool for simulating bed form dynamics, with amplitudes ranging from centimeters to meters, in real-life meandering streams 
and large rivers with arbitrarily complex, stream-restoration structures. We also seek to investigate the level of turbulence modeling sophistication required to excite the bed instability in mobile-bed systems of varying scale. To that end, we simulate dune dynamics in three different waterways with and without embedded in-stream rock structures: $(i)$ the intermediate-scale stream presently installed in the St. Anthony Falls Laboratory (SAFL) Outdoor StreamLab (OSL), with amplitudes and wavelengths in the range of $\sim 0.1 m-0.2 m$ and $\sim 0.1 m-1.5 m$, respectively; $($ ii $)$ a representative large-scale gravel bed river with dune amplitudes and wavelengths in the range of $\sim 0.5 \mathrm{~m}$ and $\sim 20 \mathrm{~m}$, respectively; and (iii) a representative large-scale sand bed river with corresponding dune characteristics of $\sim 1.5 \mathrm{~m}$ and $\sim 30 \mathrm{~m}$, respectively. In addition to the numerical simulations we also report herein experimental measurements of bed form characteristics for the OSL case, which we employ to validate the VSL3D predictions. Our simulations show that in the intermediate-scale system LES is essential for exciting the bed instability and giving rise to rich dune dynamics. In the two large-scale rivers, however, URANS is able to capture the origin and sustain migration of dunes over several months of simulated time.

The paper is organized as follows. First, we introduce briefly the hydrodynamic and morphodynamic models followed by the description of the experimental stream and virtual meandering rivers we used for simulations. Subsequently, we describe the experimental methods we employed to collect morphodynamic measurements in the OSL and present the simulation results for this case. This will be followed by the simulation results of macro-scale dunes in gravel and sand bed meandering rivers. Finally, we summarize main contribution of this work and discuss future extension of our work to simulate riverine systems during the full length of a flood hydrograph.

\section{The VSL3D model}

\subsection{Resolved flow equations}

The equations governing the instantaneous, resolved flow field for 3D, incompressible, turbulent flow are the time- or spatially-averaged continuity and Navier-Stokes equations for URANS and LES, respectively [55]. In the CURVIB method employed in VSL3D [41], the governing equations are first written in Cartesian coordinates $\left\{x_{i}\right\}$ and then transformed in curvilinear coordinates $\left\{\xi_{i}\right\}$. The transformed equations in compact tensor notation are as follows $(i, j=1,2,3)$ :

$$
J \frac{\partial U_{j}}{\partial \xi_{j}}=0
$$

$$
\frac{1}{J} \frac{\partial U_{i}}{\partial t}=\frac{\xi_{l}^{i}}{J}\left(-\frac{\partial}{\partial \xi_{j}}\left(U_{j} u_{l}\right)+\frac{1}{\rho} \frac{\partial}{\partial \xi_{j}}\left(\mu \frac{g^{j k}}{J} \frac{\partial u_{l}}{\partial \xi_{k}}\right)-\frac{1}{\rho} \frac{\partial}{\partial \xi_{j}}\left(\frac{\xi_{l}^{j} p}{J}\right)-\frac{1}{\rho} \frac{\partial \tau_{l j}}{\partial \xi_{j}}\right),
$$

where $J$ is the Jacobian of the geometric transformation given by $J=$ $\left|\partial\left(\xi_{1}, \xi_{2}, \xi_{3}\right) / \partial\left(x_{1}, x_{2}, x_{3}\right)\right|, \xi_{l}^{i}=\partial \xi_{i} / \partial x_{l}$ are the transformation metrics, $u_{i}$ is the $i^{\text {th }}$ Cartesian velocity component, $U_{i}=\left(\xi_{m}^{i} / J\right) u_{m}$ is the contravariant volume flux, $g^{j k}=\xi_{l}^{j} \xi_{l}^{k}$ are the components of the contravariant metric tensor, $p$ is the pressure, $\rho$ is the density, $\mu$ is the dynamic viscosity, and $\tau_{i j}$ is the sub-grid stress tensor for the LES model or the Reynolds stress tensor for the URANS model [55]. 
166 167

\subsection{Turbulence models}

The VSL3D incorporates both LES and URANS turbulence models implemented in the context of the CURVIB method so that they can be applied to arbitrarily complex geometric configurations. The governing equations and the detailed implementation of the models are described in $[55,64]$. Here, only a brief description of key aspects of the implementation of the two turbulence models is presented in this section.

\subsubsection{LES model}

The filtered Navier-Stokes equations (Eqns. (1) and (2)) are obtained by decomposing the velocity into resolved and unresolved components and integrating the Navier-Stokes equations over the spatial filter [85]. As a result, sub-grid stress terms appear in the momentum equations (Eqn. (2)), which are modeled using the Smagorinsky sub-grid scale (SGS) model [88]:

$$
\tau_{i j}-\frac{1}{3} \tau_{k k} \delta_{i j}=-2 \mu_{t} \overline{S_{i j}}
$$

where the overbar denotes the grid filtering operation, $\overline{S_{i j}}$ is the filtered strain-rate tensor, $\mu_{t}=C_{s} \Delta^{2}|\bar{S}|$ is the eddy viscosity, $C_{s}$ is the Smagorinsky constant, $\Delta=J^{-1 / 3}$ is the filter size calculated by box filter [85], $J^{-1}$ is the cell volume, and $|\bar{S}|=\sqrt{2 \overline{S_{i j}} \overline{S_{i j}}}$.

Traditionally, the constant Smagorinsky models use a $C_{s} \approx 0.1$ [85]. In this work, however, we employ the dynamic Smagorinsky model [42] as a sub-grid model in which the model constant $C_{s}$ evolves in time and space as a function of the flow field and is more appropriate for high $R e$ number turbulent flows like those we deal with in this study [42]. Using the dynamic Smagorinsky model, the optimal value of $C_{s}$ is selected to minimize the mean square error between the resolved stress at the grid filter and the test filter [42]. In the present numerical implementation of the SGS model, the Smagorinsky constant and the eddy viscosity are computed at the center of the cell at the beginning of each time step. Subsequently, the eddy viscosity is interpolated from the cell center to the cell face and it is used to calculate the SGS terms in Eqn. (3).

\subsubsection{URANS model}

The unsteady Reynolds-averaged Navier-Stokes equations (Eqns. (1) and (2)) are obtained by decomposing the velocity into resolved (time-averaged) and unresolved (fluctuating) components and integrating the Navier-Stokes equations over time [96]. In this study, the URANS equations are closed with the $k-\omega$ turbulence model to calculate the Reynolds stress tensor appearing in the momentum equations (Eqn.(2)).

The governing equations for the $k-\omega$ model read in generalized curvilinear coordinates as follows [96]:

$$
\frac{1}{J} \frac{\partial(\rho k)}{\partial t}+\frac{\partial}{\partial \xi_{j}}\left(\rho k U_{j}\right)=\tau_{i j} \frac{\xi_{j}^{k}}{J} \frac{\partial u_{i}}{\partial \xi_{k}}-\frac{1}{J} \beta^{*} \rho k \omega+\frac{\partial}{\partial \xi_{j}}\left(\left(\mu+\sigma^{*} \mu_{t}\right) \frac{g^{j k}}{J} \frac{\partial k}{\partial \xi_{k}}\right)
$$

$$
\frac{1}{J} \frac{\partial(\rho \omega)}{\partial t}+\frac{\partial}{\partial \xi_{j}}\left(\rho \omega U_{j}\right)=\alpha \frac{\rho \omega}{k} \tau_{i j} \frac{\xi_{j}^{k}}{J} \frac{\partial u_{i}}{\partial \xi_{k}}-\frac{1}{J} \beta \rho \omega^{2}+\frac{\partial}{\partial \xi_{j}}\left(\left(\mu+\sigma^{*} \mu_{t}\right) \frac{g^{j k}}{J} \frac{\partial \omega}{\partial \xi_{k}}\right)
$$

$$
\mu_{t}=\rho k / \omega
$$


where the closure coefficients are given as $\alpha=5 / 9, \beta=3 / 40, \beta^{*}=9 / 100$, and $\sigma^{*}=1 / 2$. The components of the Reynolds stress tensor, $\tau_{i j}$, is calculated using the Boussinesq hypothesis as follows:

$$
\tau_{i j}=-2 \mu_{t} S_{i j}+\frac{2}{3} \rho k \delta_{i j}
$$

where $S_{i j}$ is the Reynolds averaged strain-rate tensor.

\subsection{Hydrodynamic solver}

The details of the numerical method used in VSL3D for solving the mean flow and turbulence closure governing equations have already been documented extensively elsewhere $[41,9,54]$ and only a brief summary of key elements of the method will be given here.

The governing equations are discretized in space on a hybrid staggered/non-staggered grid arrangement $[43,41]$ using the second-order accurate central differencing (for LES) and QUICK scheme (for URANS) for the convective terms along with second-order accurate, three-point central differencing for the divergence, pressure gradient and viscous-like terms. The time derivatives are discretized using second-order backward differencing [54].

The discrete mean flow equations are integrated in time using an efficient, second-order accurate fractional step methodology coupled with a Jacobian-free, Newton-Krylov solver for the momentum equations and a GMRES solver enhanced with multigrid method as preconditioner for the Poisson equation. For additional details regarding the numerical method used in the hydrodynamic solver see [31, 41, 9, 54]. The flow solver computations for complex open channel flow environments are already validated by Kang et al. [54].

Geometrically complex computational domains are handled using the sharp-interface CURVIB method [41]. The computational domain consists of a straight channel that outlines the actual channel under consideration and is sufficiently deep to contain the entire sediment/water interface at all times. The computational domain is discretized with a boundary-fitted curvilinear mesh while the sediment/water interface, rigid side walls, and embedded rock structures are discretized with an unstructured grid and immersed in the background domain as a sharp-interface in accordance with the CURVIB formulation. The governing equations are solved at the background grid nodes in the fluid phase (fluid nodes) with boundary conditions specified at fluid nodes in the immediate vicinity of the sediment/water and in-stream rock structure/water interfaces (denoted as immersed boundary (IB) nodes). All nodes inside the sediment layer and in-stream structure domains (denoted as external nodes) are blanked out from the computations. Boundary conditions for the velocity components and turbulence quantities are reconstructed at all IB nodes using the wall modeling approach within the CURVIB framework (see next section). The efficient ray-tracing algorithm developed by Borazjani et al. [9] is applied to re-classify the grid nodes each time when the bed geometry changes due to local scour. The wall function approach is adopted to compute the velocity components at IB nodes and the bed shear stress on the bed surface (for more details see [64]). An effective roughness height of $k_{s}=3 d_{50}$ is adopted for mobile beds, side walls, and in-stream rock structures.

Finally, it is important to mention that VSL3D is fully parallelized using the message passing interface (MPI) communication standard to run on parallel high-performance clusters. 


\subsection{Morphodynamic model}

In this section we outline the applied mathematical equations that govern the temporal variation of the mobile geometry of the sediment/water interface. We consider the case for which sediment transport occurs as bed- and suspended load. In this work, we assume that the bed-load occurs within bed-load layer $\left(\left\|\delta_{\mathbf{B L}}\right\|\right)$, which is located immediately above the bed elevation. The suggested ranges for the bed-load layer thickness in intermediate- and large-scale channels are $d_{50}-5 d_{50}$ and $0.01 H-0.04 H$ ( $H$ is mean flow depth), respectively $[99,93,98,2]$. Using a separate calibration study (see [62]), the bed-load layer thickness for the intermediate- and large-scale rivers in this paper is set equal to $2 d_{50}$ and $0.02 H$, respectively.

The temporal variation of the bed elevation is governed by the sediment continuity equation, the so-called Exner-Polya equation [79] as follows:

$$
(1-\gamma) \frac{\partial z_{b}}{\partial t}+\nabla \cdot \mathbf{q}_{B L}=D_{b}-E_{b}
$$

where $\gamma$ is the sediment material porosity, $z_{b}$ is the bed elevation above a datum level, $\nabla$ denotes the divergence operator, $\mathbf{q}_{B L}$ is the bed-load flux vector and show the contribution of bed-load to the bed change. $D_{b}$ is the net deposition onto the bed and $E_{b}$ is the net entrainment from the bed cell. The right hand side of Eqn. 8 represents the net sediment material exchange between the flow domain and the bed load layer and is known as the contribution of suspended load to the bed elevation change. The bed- and suspended load models are described in the next section.

In order to prevent the bed slope from exceeding the sediment material angle of repose, a mass-conservative sand-slide algorithm has been developed and incorporated (for more details see $[60,61,59])$. After solving the Exner-Polya equation and computing the new bed elevations, the entire bed is swept to identify bed cells at which the maximum bed slope (at the centroid of triangular bed cells) is larger than the angle of repose.

\subsubsection{Bed load}

In the CURVIB method, the bed mesh is created by using an unstructured triangular grid. Eqn. 8 is then discretized and solved using a finite volume method suitable for unstructured grids. Using the divergence theorem, the bed-load term in Eqn. 8 can be discretized at a given triangular element on the bed as follows:

$$
\nabla \cdot \mathbf{q}_{B L}=\frac{1}{A_{h}} \sum_{i_{e}=1,2,3}\left[\mathbf{q}_{B L} \cdot\left(d \mathbf{s} \times \delta_{B L}\right)\right]_{i_{e}}=-\frac{1}{A_{h}} \sum_{i_{e}=1,2,3}\left[\mathbf{q}_{B L} \cdot \mathbf{n}\right]_{i_{e}}
$$

where $A_{h}$ is the projection of triangle bed cell area on the horizontal plane or horizontal projected area of the cell face. The summation is carried out over the three edges of the triangular element $\left(i_{e}=1,2,3\right)$. $d \mathbf{s}$ is the vector along a cell edge with length equal to the edge length; $\delta_{B L}$ is the vertical vector along the $z$-axis with length equal to the bed-load layer thickness $\delta_{B L}$; and $\mathbf{n}\left(d \mathbf{s} \times \delta_{B L}\right)$ is the unit normal vector to the cell face edge. The bed load flux vector, $\mathbf{q}_{B L}$, is calculated as follows [60]:

$$
\mathbf{q}_{B L}=\psi\|d \mathbf{s}\| \delta_{B L} \mathbf{u}_{B L}
$$

where $\psi$ is the local sediment concentration on the bed, $\|d \mathbf{s}\|$ is the length of edge $i_{e}$, and $\mathbf{u}_{B L}$ is the flow velocity vector parallel to the bed surface at the edge of the bed load 
layer. From flow field computations, the time-accurate computed velocity vector and bed shear stress are projected onto the cell centroid at the edge of bed load layer by applying the law of the wall [60]. The bed concentration $\psi$ is computed at each cell center on the bed using van Rijn's equation [93]. Once all required variables have been computed at the cell centroid of a bed cell, the bed-load flux $\mathbf{q}_{B L}$ at the cell face is calculated using the GAMMA scheme which is a second-order convective scheme [60] and a blend between the diffusive first-order upwind scheme and the dispersive second-order accurate central differencing scheme [49]. The critical bed shear stress is also computed using Shield's criterion for the flat bed critical bed shear stress $\left(\tau_{* c 0}\right)$ and then corrected for transverse and longitudinal bed slopes (for details see [64]).

\subsubsection{Suspended load}

The suspended sediment is modeled as a passive scalar whose transport is governed by the following advection-diffusion equation [98, 101, 102, 17, 18, 67]:

$$
\frac{1}{J} \frac{\partial(\rho \psi)}{\partial t}+\frac{\partial}{\partial \xi^{j}}\left(\rho \psi\left(U^{j}-W^{j} \delta_{i 3}\right)\right)=\frac{\partial}{\partial \xi^{j}}\left(\left(\mu+\sigma^{*} \mu_{t}\right) \frac{G^{j k}}{J} \frac{\partial \psi}{\partial \xi^{k}}\right)
$$

where $W^{j}=\left(\xi_{3}^{j} / J\right) w_{s}$ is the contravariant volume flux of suspended sediment, $\sigma^{*}$ is the Schmidt number $(=0.75)$, and $w_{s}$ is the settling velocity of nonspherical sediment particles which is computed by van Rijn's formula [93].

At the mobile sediment/water interface we employ the approach proposed by Chou and Fringer [17] to specify boundary conditions for $\psi$ using van Rijn's pickup function [93]. At rigid walls and the outlet of the flow domain we employ a Newman, zero-gradient boundary condition while for the free-surface boundary we assume no-mass flux condition as follows [93]:

$$
w_{s} \psi+\left(\mu+\sigma^{*} \mu_{t}\right) \frac{\partial \psi}{\partial x_{3}}=0
$$

Third-order WENO [52] and second-order central differencing schemes are employed for the spatial discretization of advection and diffusion terms in the sediment concentration transport equation (Eqn. (11)), respectively. Additionally, the second-order backward differencing scheme is used for the time integration. The sediment concentration equation is solved using the fully implicit Jacobian-free Newtons method at every time step after the velocity fields are obtained by the fractional step method (For more details see [54]).

Now we focus our attention to the right hand side of Eqn. (8), where we incorporate the computed suspended sediment concentration into the bed change calculation as the net flux of sediment material across the interface between the flow and the bed-load layer. The deposition rate at this interface is modeled as $D_{b}=w_{s} \bar{\psi}_{b}$ [12] where $\bar{\psi}_{b}$ is the sediment concentration immediately above the bed-load layer and is computed by a quadratic interpolation procedure from calculated $\psi$ in the stratified flow domain (for more details on the interpolation method see [43]). The entrainment rate is also modeled by assuming an equilibrium condition under which the $E_{b}$ would be equal to $D_{b}$ so that $E_{b}=w_{s} \psi_{b}[93,12]$. Therefore, after incorporating the bed and suspended loads, the non-equilibrium sediment continuity equation (Eqn. (8)) can now be rewritten as

$$
(1-\gamma) \frac{\Delta z_{b}}{\Delta t_{s}}+\frac{1}{A_{h}} \sum_{i_{e}=1,2,3}\left[\mathbf{q}_{B L} \cdot \mathbf{n}\right]_{i_{e}}=w_{s}\left[\bar{\psi}_{b}-\psi_{b}\right]
$$


where $\Delta z_{b}$ is the bed elevation change over morphodynamic time step $\Delta t_{s}$.

\subsection{Hydro-morphodynamic coupling}

To simulate the coupling between the flow and morphodynamics, we employ a partitioned fluid-structure interaction (FSI) approach [9]. That is, we partition the problem into the fluid and sediment domains and solve the governing equations for the stratified flow and the bed morphodynamics separately in each domain accounting for the interaction of the two domains by applying boundary conditions at the sediment/water interface. More specifically, to solve the equations governing the flow, boundary conditions are specified on the bed in terms of the bed surface location, rate of bed elevation change, and sediment concentration on the bed. On the other hand, to solve the bed evolution equation (Eqn. (13)) the velocity components, bed shear stress, and sediment concentration from the stratified flow domain are required to calculate: $(i)$ the sediment fluxes in the left hand side of Eqn. (13), and (ii) the net sediment flux at the interface of stratified flow and bed-load layer in the right hand side of Eqn. (13). For the details of how we prescribe the boundary conditions in the two domains see [60]. In this work, we found that the loose-coupling FSI approach in which the boundary conditions at the sediment/water interface are obtained from the domain solutions from the previous time level (explicit in time) is robust enough for the problems considered and thus we employed it in all subsequent simulations. The loose-coupling flow-bed interaction method we employed in this study is described in detail elsewhere (see [64, 63]).

\subsection{Variable time-stepping technique}

Using the partitioned FSI approach [9] in the previous section, we are able to use different time steps for the flow and sediment transport problems. This capability is especially important for two-phase flow problems in which the time scales of the various phases can be significantly different. More specifically, the flow time scale for our case, and for most geophysical flow applications, is significantly smaller than the time scale of bed morphodynamics [73]. Dimensional analysis of the governing equations for flow and morphodynamics show that the erosion kinetics are significantly slower than the flow kinetics and that the time scale of bed change is approximately two orders of magnitude greater than that of the flow field [73]. From a practical point of view, it is also important to have the capability of utilizing two different time steps for the flow and bed-change calculations as the mobile bed of a natural waterway requires integration over a very long physical time to reach quasi-equilibrium. Therefore, being able to use larger time steps for the bed change calculations than the time step used to integrate the flow equations can significantly reduce the computational cost of such two-phase flow simulations.

To mitigate the computational challenges created by the disparate time scales of the two phases, we have employed a dual-time-stepping technique along with a quasisynchronization approach in the VSL3D making sure to have a time accurate solution for the computed flow field. A detailed description of the employed dual-time-stepping technique is presented elsewhere (see [63]).

\section{Experimental observations in the OSL}

In this section we describe the method we used to collect the bed form data from the OSL for model validation. This field-scale experimental channel has independent control 
over water and sediment feed rates (see Figure 2). The OSL is a sand-bed meandering stream with a live-bed pool and riffle sequence that is approximately $50 \mathrm{~m}$ long, $2.7 \mathrm{~m}$ wide, and $0.1 \mathrm{~m}$ and $0.3 \mathrm{~m}$ deep at base and bankfull flow, respectively. The wavelength of the meander is approximately $25 \mathrm{~m}$, and the channel was initially constructed as a modified sine-generated curve with a moderate sinuosity of 1.3 [82]. In Table 1 we show the characteristics of OSL channel at bankfull flow condition.

Table 1: Characteristics of bankfull flow condition in the OSL: median grain size of bed material $d_{50}$ mean channel width $B$, flow discharge $Q$, mean flow depth $H$, bed slope $S_{o}$, sinuosity $s$, wavelength of meander $\lambda_{m}$, and sediment feed rate $q_{s}$.

\begin{tabular}{lllllccll}
\hline Stream & $d_{50}(\mathrm{~cm})$ & $B(\mathrm{~m})$ & $Q\left(\mathrm{~m}^{3} / \mathrm{s}\right)$ & $H(\mathrm{~m})$ & $S_{o}$ & $s$ & $\lambda_{m}(\mathrm{~m})$ & $q_{s}(\mathrm{~kg} / \mathrm{min})$ \\
\hline OSL & 0.07 & 2.7 & 0.284 & 0.3 & $7 \times 10^{-3}$ & 1.3 & 25 & 4.0 \\
\hline
\end{tabular}

The OSL has a mobile sediment median grain size of $0.7 \mathrm{~mm}$, which is fed at the inlet. The riffles consist of gravel and cobble material ranging from $10 \mathrm{~cm}$ to $15 \mathrm{~cm}$ in diameter, which postulates a critical bed shear stress that is significantly larger than the maximum bed shear stress. Therefore the riffle topography is mostly fixed. More details of OSL characteristics are reported in a series of papers (see $[54,56,55,63])$. The experimental observations of bed form evolution in the OSL include systematic observations of bed form migration, as well as quantitative measurements of the bed form characteristics, such as amplitude, wavelength, and celerity throughout the meander of OSL using infrared camera observations.

Simultaneous sub-aqueous bed topography and water surface elevation data were collected with a computer controlled data acquisition cart outfitted with a sonar probe (Panametrics C304) and ultrasonic transducer (Massa M300). A downward looking laser displacement sensor (Keyence LKG) was used to measure above water topography. The cart with affixed sonar probe can be used to provide a detailed time-averaged view of the bed or time series of bed elevation with a window of approximately $1.3 \mathrm{~m}$. The cart is spatially registered in the local OSL coordinate system using a total station (Sokkia 330RK) and permanent benchmarks along the OSL channel. Repeat scans along a single transect were used to measure bed elevation changes (due to bed form migration) and time-averaged scans from each cart location were stitched together to create highresolution ( $\mathrm{cm}$ spacing) topographic and water surface images of the entire OSL channel. Bed form data were collected during a quasi-equilibrium bankfull flood condition (Table 1) for a case where cross vanes were installed bracketing the middle meander bend. In this case, the riffles were removed and cross vanes were installed in their place. A color charged-coupled device (CCD) camera mounted at $x=19.16 \mathrm{~m}, y=25.24 \mathrm{~m}$, and $z=246.43 \mathrm{~m}$ in OSL coordinates (see Figure 2) was used to view migrating bed forms. Water depth was estimated from the red channel of the color images as it produced the best contrast between bed form crest and trough. To remove high image intensity (bright) contamination introduced by sun glint and paper tracers from the color images used to track bed forms, the image intensity at each pixel in the image was compared between the 37 images collected over a $5 s$ period. The lowest intensity sample at each pixel was retained, resulting in the 37 images being merged into a single darkest image where sun glint and paper tracers were removed. A time-averaged sonar survey was used to calibrate the Beer-Lambert law [72] relating image intensity and depth. The video 
method can generate a synoptic view of bed form migration around the entire meander. Once water depths were determined, the method developed by Clarke and Werner [21] to observe subaqueous features in the surf zone was implemented to account for the apparent displacement of submerged features away from the camera. Space-time images of the stream bed were created from the processed images by extracting pixels along 5 downstream profiles. Individual bed forms were digitized in the space-time images and bed form crest height and wavelength were determined. Bed form migration rate was calculated using the cross-correlation between the initial bed profile and successive profiles [72]. The time-averaged crest height, wavelength, and bed form migration rate were estimated upstream of the meander bend, at the bend apex, and downstream of the meander bend for comparison with model results.

In Figure 3 we show the meander pool zone of the OSL channel in which we observed bed form evolution. Bed forms at different parts of the pool zone have distinct characteristics. Near the inlet of the pool (upstream of the meander apex; identified with the blue line in Figure 3) bed forms are smaller in size and move faster. As they pass through the channel they merge together and grow in size. Bed forms in the red zone (near the apex in Figure 3) are larger with lower migration velocity than the blue section (Figure 3 ). In Table 3 we show the range of measured dune characteristics for these three areas within the OSL meander bend.

\section{Simulation results for intermediate-scale dunes in the OSL}

In this section we present the results of the coupled hydro- and morphodynamics simulation of OSL and subsequently discuss the dynamics of the numerically captured dunes and compare their characteristics with the experimental data. We employ the VSL3D to carry out LES of coupled turbulent flow and morphodynamics in the OSL with three different commonly utilized rock structure configurations around the test meander: three rock vanes, three J-hook vanes, and three bendway weirs under the bankfull flow condition presented in Table 1 . All of these simulations are run using the fully synchronized time-stepping method in which the same time step is used for the flow and morphodynamics calculations. Simulations for these test cases, with a constant sediment feed rate of $4 \mathrm{~kg} / \mathrm{min}$, are continued for $\sim 10$ hours at which time the 3D dune waves are at their equilibrium state (see below sections). For each test case, we develop a fully turbulent flow at the inlet of the channel in a separate simulation and this turbulent boundary layer was fed at the inlet during the coupled simulation as the inlet boundary condition. The water free surface is assumed to be a rigid-lid boundary condition. The sediment material is numerically fed at the inlet resampling the continuous circulation of sediment materials. The details of the rock structures for each case are reported elsewhere (see $[83,77,89,63]$ ).

We mesh the OSL channel using a structured and curvilinear background grid that outlines the OSL channel meandering shape and contains its side walls, rock structures, and the sediment layer (Figure 2). The geometries of the side walls and rock structures were collected at $\mathrm{cm}$ resolution using the data acquisition cart described above, meshed using unstructured triangular grids, and treated as immersed boundaries (see Figure 2). In Table 2 we show the details of the computational grid system and time step used for each test case. 
Table 2: Computational parameters used for the three test cases for the OSL simulations. $N_{x}, N_{y}$, and $N_{z}$ are the number of grid nodes in streamwise, spanwise, and vertical directions, respectively. $z^{+}$ is the minimum normal near-wall grid spacing in wall units, $n_{s}$ and $n_{b}$ are the number of nodes used to discretized the unstructured triangular mesh at the sediment/water and rigid wall/water interface, respectively, and $\Delta t$ is the time step. The rigid walls include the OSL side walls and rock structures

\begin{tabular}{cccccc}
\hline Test case & $N_{x} \times N_{y} \times N_{z}$ & $z^{+}$ & $n_{s}$ & $n_{b}$ & $\Delta t$ \\
\hline 1. rock vanes & $1201 \times 133 \times 61$ & 90 & 35461 & 541 & 0.01 \\
2. J-hook vanes & $1261 \times 137 \times 61$ & 75 & 36201 & 815 & 0.01 \\
3. bendway weirs & $1201 \times 133 \times 61$ & 85 & 34325 & 538 & 0.01 \\
\hline
\end{tabular}

It is important to note that we also employed VSL3D in URANS mode (with $k-\omega$ closure) using the same grid system to simulate the bed form development for each of the OSL test cases described in Table 3. The URANS simulations for all of these test cases were successful in capturing the overall sediment transport phenomena and bed elevation at quasi-equilibrium in terms of scour depth and point bar location and deposition height. For more detail on the morphodynamic results of these simulations readers are referred to [63]. However, due to its inherently diffusive nature, the URANS simulations were not able to capture the turbulent eddies that excite the bed instabilities and give rise to the initiation and development of bed forms $[18,37,64,63]$. Therefore, at this scale the URANS model could not simulate dune dynamics and for that reason, only the LES results are reported herein. We note that compared to the spatial resolution used in [64], the LES grids we employ herein are up to an order of magnitude coarser $(\sim 10$ million nodes vs. up 90 million nodes). However and as we will show below, such resolution is adequate for exciting the very energetic, large-scale coherent structures, induced by the curvature of the channel, the complex bathymetry and the embedded rock structures, that dominate flow and sediment transport processes in meandering waterway. This is an important finding as it shows that relatively coarse grid LES can be used to obtain quite reasonable morphodynamic evolution in complex waterways, at least at the intermediate scale.

\subsection{Test case 1: OSL with three rock vane structures}

We simulate sediment transport and bed morphodynamics in the bankfull OSL (see Table 1) with three mounted rock vane structures. The computational details of this simulation are also shown in Table 2. The simulations start from the flat bed condition. Shortly after the start of the coupled hydro-morphodynamic iterations energetic bed forms emerge, grow, and migrate. Animation videos we have created (not included herein) show that the presence of rock vanes in the meander pool zone and the coherent structures they induce act to perturb the bed and trigger the emergence of bed forms. Bed forms also initiate near the point bar where the combination of bed shear stress and sediment supply suits the formation of bed forms. As bed forms approach the downstream riffle zone they are washed out due to the increased turbulence levels near the bed at this region. As shown in the high resolution LES simulation of Kang et al. [54], the high levels of turbulence kinetic energy (TKE) in the riffle zone of the OSL are associated with large roughness elements in this region of the bed.

In Figure 4 we show snapshots of the simulated dynamically-rich dunes for this case. The four dunes observed on the bed at time instant $t 1$ in Figure 4 are denoted as $B 1$ 
to $B 4$. At time instant $t 2 \sim t 1+10 \mathrm{~min}$, these bed forms have migrated downstream, each at a different speed depending on its length scale. Once the bed forms approach the riffle zone (which starts immediately after the meander pool zone) they merge and finally wash away in this region. At time instant $t 3 \sim t 2+10 \mathrm{~min}$ we notice the migration and growth of $B 1$ and $B 2$, while $B 3$ and $B 4$ merge together. Similar merging phenomena have also been observed in the OSL where two or smaller bed forms merge to form a larger one near the end of meander pool zone. At time instant $t 4 \sim t 3+10 \mathrm{~min}$, dunes $B 3$ and $B 4$ disappear (by entering into the riffle zone) and a newly formed bed form, $C 1$, appears at upstream of the third rock-vane. As the simulation goes on, this sequence of dune growth, migration, merging and disappearance at the riffle zone is repeated again.

The simulated bed forms in this case are found to have an average amplitude, wavelength, and celerity of $1-16 \mathrm{~cm}$ and $23-135 \mathrm{~cm}$, and $12-29 \mathrm{~cm} / \mathrm{min}$, respectively. Comparing these results with the measured dune characteristics in Tables 3 , it is clear that the simulated dunes are well within the range of typical bed forms observed experimentally in the OSL through camera observations.

\subsection{Test case 2: OSL with three J-hook structures}

In this case, we investigate the sediment transport process in the OSL with three Jhook vane in-stream structures installed along the outer bank and under the bankfull flow condition (see Table 1). A J-hook vane structure consists of a rock vane with additional rocks attached to its tip thus forming a J or hook pattern (see [83]). Gaps between the rocks at the tip of the structure cause the oncoming flow to converge between the gaps, creating complex 3D flow patterns around the structure and sediment material passage through the gaps (for more details see [59]).

The details of the computational grid for the coupled hydro-morphodynamics simulation are shown in Table 2. The background mesh for the flow field computation was stretched so that the gap region in the hook part of the J-hook can be resolved with at least 10 grid nodes between the gaps. As a result of this finer mesh resolution and to ensure that the resulting grid has aspect ratios comparable to those for case 1 , the minimum normal near-wall grid spacing for this case is smaller than for test cases 1 and 3 (see Table 2). Details of rock size geometrical characteristics of the installed J-hook vanes are reported elsewhere [89].

The simulation for this test case was continued for several hours during which the formation, growth, and migration of multi-scale dunes along with their passage through the gaps of the hook part of J-hook vane were observed (see Figure 5). As Khosronejad et al. [59] reported, the J-hook vane structures have several openings/gaps between the individual rocks in their hook parts that will naturally lead to the passage of waveforms through them. As we have experimentally observed in this test case, the passage of sediment mass through the gaps of the hook section occurs continuously. As shown in Figure 5, similar phenomena are also observed in the simulation where sediment material migrates continuously toward the gap region and passes through it. Once a patch of moving bed material reaches the upstream of a gap its velocity is locally reduced. Soon after such a patch enters the gap between individual rocks, however, it speeds up due to the contraction effect as it passes the hook portion of the structure. As a result of this local acceleration through the gaps the celerity of the waveforms is increased in the vicinity of the hook. Our calculations show that for this test case, most of the sediment material $(\sim 85$ percent) is transported through the opening region between the inner 
bend and J-hook vanes in the form of dune waves, while only $\sim 15$ percent of material pass through the gaps of hook part (in the form of dunes). The tip of the J-hook vane (i.e. the single rock that is farthest away from the outer bend) gives rise to turbulent perturbations that trigger the emergence of bed forms. Bed forms also initiate near the point bar as for the previous case. Similar to test case 1, as bed forms approach the downstream riffle zone they are washed out due to the high levels of near bed turbulence.

The mechanism that we described for the dune waves in this test case can be readily seen in Figure 5 where we show the instantaneous snapshots of the simulated dune dynamics. The four dunes observed on the bed at time instant $t 1$ in Figure $5 \mathrm{a}$ are denoted as $B 1$ to $B 4$. At time instant $t 2 \sim t 1+20 \mathrm{~min}$, the dunes have migrated downstream, each at a different velocity depending on its length scale. Additionally, at time instant $t 2$ two newly emerged bed forms of $C 1$ and $C 2$ can also be spotted in Figure 5b. By comparing the color maps in Figures $5 \mathrm{a}$ and b, one can also notice the passage of sediment though the openings of the hook parts which is associated with the movement of waveforms between the individual rocks. The dune $B 4$ exits the pool zone and is washed out in the riffle zone which is characterized by its high turbulence kinetic energy [54]. At time instant $t 3 \sim t 2+10 \mathrm{~min}$ we notice that $B 1$ and $C 1$ merge together forming a larger dune, which now can migrate faster (Figure $5 \mathrm{c}$ ). In the meantime, $B 2$ migrated further downstream approaching the last J-hook structure. $C 2$ migrates toward the riffle zone with a lower speed that can be attributed to its small characteristic size. The growth rate of this last bed form, $C 2$, is influenced by the availability of sediment material in this region and is limited as the upstream waveforms merge to form larger dunes. At this moment, the dune $B 3$ is about to exit the pool zone entering the riffle zone where it will soon be washed away. It is noteworthy that such merging phenomena have also been observed experimentally in the OSL where two or smaller bed forms merge to form larger ones. At $t 4 \sim t 3+10 \mathrm{~min}$ dune $C 1-B 1$, which is formed by merging $C 1$ and $B 1$, is seen to have migrated faster and caught up with the $B 2$ near the tip of the third J-hook structure (Figure $5 \mathrm{~d}$ ). Some portions of dune $C 1-B 1$, which are located more toward the outer bend migrated with a lower velocity and separated. These portions are shown as a residual material in the middle of channel between the second and third J-hook vanes in Figure $5 \mathrm{~d}$. Another newly formed dune $D 1$ has also appeared near the inner bend of the channel where the sediment supply is sufficient for bed form emergence. The above sequence of dune emergence, growth, migration, merging, and disappearance at the riffle zone is repeated continuously.

The simulated bed forms for this case are found to have an average amplitude, wavelength, and celerity of $1-15 \mathrm{~cm}, 18-140 \mathrm{~cm}$, and $14-28 \mathrm{~cm} / \mathrm{min}$, respectively. These computed quantities are well within the range of typical bed forms observed experimentally in the OSL (see Table 3).

\subsection{Test case 3: OSL with three bendway weirs}

Bendway weirs, or stream barbs are single-arm rock structures placed along stream banks that extend from the bank into the channel flow and are submerged in all but base flow conditions $[77,89]$. Bendway weirs are flat or nearly flat across their length and mitigate erosive flow patterns through weir mechanics [33]. They have been shown to be effective in preventing or limiting bank erosion by modifying the helical flow patterns of secondary currents that is typically associated with channel meanders (for details on the resolved helical flow patterns in the OSL, see [56]). The presence of these in-stream 
structures relocates the erosive flow patterns from the vulnerable outer bank toward the center of the channel [32]. Bendway weirs specifically protect the bank by disrupting velocity gradients in near-bed regions, deflecting currents away from the outer bank by forcing flow perpendicularly over the weir, and shifting the channel thalweg to the streamwise end of these rock structures [70, 89].

In this work, we investigate the sediment transport process in the OSL with three installed bendway weirs under the bankfull flow condition (see Table 1) to study the characteristics of dune waves in the OSL where bendway weirs are present.

Like the other test cases, the scanned geometry of the OSL and bendway weirs were used to create the computational mesh for both flow domain, rigid walls, and sediment layer (for more details of the installed bendway weir in the OSL see [89]). In Table 2 we show the details of the computational grid for this coupled flow and morphodynamics simulation. As for the previous cases, the simulation was continued for several hours during which the formation, growth, and migration of multi-scale dunes were observed (see Figure 6).

In Figure 6 we show the instantaneous snapshots of the numerically captured bed forms for this test case. The five dunes observed on the bed at time instant $t 1$ in Figure 6 a are denoted as $B 1$ to $B 5$. Three of these dunes (i.e., B1, B2, and B4) are newly formed. $B 5$ is the largest dune in this figure that resulted from the merging of other bed forms at an earlier time instant. At time instant $t 2 \sim t 1+10 \mathrm{~min}$, the dunes have migrated downstream, each at a different velocity depending on its length scale. For example, the bed form B5, which was the largest (see Figure 6a) migrates faster than other smaller ones and as shown in Figure $6 \mathrm{~b}$ it has exited the pool zone of the OSL meander. At time instant $t 2$ in Figure $6 \mathrm{~b}$ we also notice a newly formed dune called $C 1$. The bed form $B 3$ partially merged with $B 2$ and $B 4$ (Figure $6 a$ ) to form $B 2-B 3$ and $B 3-B 4$ (Figure $6 \mathrm{~b})$, respectively. At a later time, $t 3 \sim t 2+10 \mathrm{~min}, B 3-B 4$ merges with $C 1$ to shape a larger dune called $B 3-B 4-C 1$ (Figure 6c). As bed forms merge the resulting bed form grows in size and migrates slower. This process can be seen in Figure $6 \mathrm{~d}$ where four smaller bed forms merge to result in a large dune called $B 2-B 3-B 4-C 1$ (at $t 4 \sim t 3+10 \mathrm{~min})$. This merged dune is at roughly at the same location as $B 5$ in $t 1$.

The simulated bed forms for this case are found to have an average amplitude, wavelength, and celerity of $1-17 \mathrm{~cm}, 21-120 \mathrm{~cm}$, and $10-26 \mathrm{~cm} / \mathrm{min}$, respectively. Once again, these computed quantities are well within the range of typical bed forms observed experimentally in the OSL (see Table 3).

\subsection{Statistical analysis of intermediate-scale dunes in the OSL}

As we have shown in the previous section, the numerically and experimentally captured dunes in the OSL with different in-stream rock structures have similar characteristics, which are well within the range of bed forms observed experimentally in this channel. Thus, in this section we only present the simulation results for the dynamics of dune waves that are observed in test case 3 , which is the OSL simulation with three bendway weirs.

In Figure 7 we show an instantaneous snapshot of the bed elevation profile of the numerically captured bed forms along the centerline of the pool zone of the OSL. With reference to Figure 3, we identify herein the three regions of the OSL as blue, red and green, depending on the characteristics of the experimentally observed bed forms. The 
bed forms initiate near the inlet of the pool zone, marked with blue in Figure 3, where they are smaller in amplitude and wavelength, and migrate faster. As they grow larger they enter the red zone of the OSL (Figure 3). At this stage they are moving slightly slower, while their amplitude and wavelength increase. The simulated dune waves reach their maximum height in the red zone where they grow as large as $17 \mathrm{~cm}$ in amplitude. The three stages of the dune wave development along the pool zone of the OSL (for test case 3) can be readily seen in Figure 7 . It is important to note that the larger dune waves often result from the merging of smaller size bed forms that are migrating in the green zone of OSL channel (Figure 3). As we described in section 3, similar scenarios of dune wave evolution in the OSL were also experimentally observed. More importantly, the streamwise extent of the experimentally observed three distinct regions in the pool zone of the OSL (see Table 3) is in good overall agreement with the numerical simulations.

Table 3: Characteristics of measured dunes in the OSL, including amplitude $\Delta$, wavelength $\lambda$, and celerity $C$. Different zones of OSL channel are shown in Figure 3.

\begin{tabular}{llll}
\hline & $\Delta(\mathrm{cm})$ & $\lambda(\mathrm{cm})$ & $C(\mathrm{~cm} / \mathrm{min})$ \\
\hline Blue zone (near the inlet) & 2 & 30 & 30 \\
Red zone (near the apex) & 7 & 71 & 18 \\
Green zone (near the outlet) & 12 & 142 & 8 \\
\hline
\end{tabular}

In Table 4 we compare the range of dune characteristics observed in the measurements and simulations in the OSL. Furthermore, in Table 5 we present the mean values of different characteristics and root-mean-square $(R M S)$ error of the simulated bed forms. The $(R M S)$ error is defined as

$$
R M S=\frac{\overline{\phi_{c}}-\overline{\phi_{m}}}{\overline{\phi_{m}}} \times 100
$$

where $\overline{\phi_{c}}$ and $\overline{\phi_{m}}$ are the mean values of wave characteristics for simulated and measured bed forms, respectively. As shown in Table 5, the discrepancies between the measurements and computations notwithstanding, however, the mean amplitude, wavelength, and celerity of simulated dunes are within $4 \%, 6 \%$, and $9 \%$ of the measured ones, respectively. Thus, the numbers in Tables 4 and 5 clearly show that the numerically captured dunes are in very good agreement with those experimentally observed under similar flow and sediment feed conditions.

Table 4: Range of amplitude $\Delta$, wavelength $\lambda$, and celerity $C$ for the measured and numerically captured (test case 1,2 , and 3 ) dunes in the OSL.

\begin{tabular}{llcl}
\hline & $\Delta(\mathrm{cm})$ & $\lambda(\mathrm{cm})$ & $C(\mathrm{~cm} / \mathrm{min})$ \\
\hline Measured & $2-12$ & $30-142$ & $8-30$ \\
Simulated & $1-17$ & $18-140$ & $10-29$ \\
\hline
\end{tabular}

To summarize the characteristics of the simulated dunes, contours of bed elevation during the first $1.4 \mathrm{hr}$ of the simulation are plotted in $s-t$ form (Figure 8). The horizontal axis $s$ in this figure is the arc length along the OSL channel centerline within the pool zone, the vertical axis $t$ measures time since the start of the coupled simulation, and the 
contours shown are those of the instantaneous bed elevation $z=z(s, t)$. Such plots are used extensively to characterize the spatial and temporal evolution of bed forms since they provide an effective way to illustrate a number of important physical phenomena $[69,22,37]$. For example, the slope of the characteristic lines that emerge in this plot is inversely related to the bed form celerity while the horizontal spacing of the topography contours along $t=$ constant lines provides the amplitude of sand waves. It is evident from Figure 8 that bed features of various sizes and celerities appear and evolve with time. A well-known feature of bed forms, which has been observed in many experiments (e.g. see $[24,94])$, is that the celerity of bed forms decreases with time. This feature is clearly evident in Figure 8 by the continuously steepening upward slope of the characteristic lines. Fast traveling, small-scale bed forms in the blue region of the OSL (see Figure 3) are seen to initially appear and merge to form larger-scale, slower traveling bed forms in the red and green zones, respectively. In particular, the three different stages of sand wave development appear as blue, red and green zones in Figure 7 can also be readily identified in Figure 8 (the dashed blue, red, and green lines in this figure).

Table 5: Statistical characteristics of measured and simulated (test case 1, 2, and 3) dunes in the OSL, including mean amplitude $\bar{\Delta}$, mean wavelength $\bar{\lambda}$, mean celerity $\bar{C}$, and $R M S$ error (Eqn. 14).

\begin{tabular}{llll}
\hline & $\bar{\Delta}(\mathrm{cm})$ & $\bar{\lambda}(\mathrm{cm})$ & $\bar{C}(\mathrm{~cm} / \mathrm{min})$ \\
\hline Measured & 7.3 & 88.1 & 15.7 \\
Simulated & 7.1 & 81.7 & 18.2 \\
$R M S$ error & 4.3 & 6.4 & 9.5 \\
\hline
\end{tabular}

Now we focus our attention on quantifying the statistical properties of the simulated dune waves in the OSL as well as examining the spectral characteristics of the bed elevation for one of the three simulated cases, test case 3. Previous studies via laboratory experiments, field observations, and numerical simulations have revealed that natural bed forms obey universal scaling laws. Hino [46] and Jain and Kennedy [48], for instance, performed spectral analysis of their experimentally measured topographic data. Their spectral analysis revealed power law relations of the frequency spectra, with exponents of $f^{-2}$ and $f^{-3}$ for high and low frequencies, respectively [46, 48]. The root-mean-square ( rms) of bed elevation fluctuations sampled over a range of length scales has also been shown to exhibit power scaling law $[51,36,50,37]$, which can be related to the roughness of the evolving bed [5].

Following Jerolmack and Mohrig [50], Escauriaza and Sotiropoulos [37], and Khosronejad and Sotiropoulos [64], we evaluate the rms of the computed bed elevation, as a function of the length scale $\Delta s$ along the space vector of $s$ which follows the centerline of the OSL (for more details on the fluctuation method see [37, 19]). Herein we present a brief summary of this method. For a given instant in time $t$, we sample the bed elevation series along the $s$ space vector as $z=z(s)$. This sampling is carried out using a filter width $\Delta s$ and the $R M S$ of the resulting bed elevation as function of $\Delta s$ is computed as follows:

$$
z_{\Delta_{s} s}=\left[\frac{1}{N} \sum_{i=1}^{N}\left(z_{i}-\overline{z_{b}}\right)^{2}\right]^{\frac{1}{2}}
$$


where $z_{i}$ is the bed elevation at the ith point along the $s, \overline{z_{b}}$ is the averaged bed elevation along the centerline, and $N$ is the total number of data points along $s$ at intervals of $\Delta s$.

The scale invariance of the spatial fluctuations produced by the bed forms geometry determines an increase in magnitude with the length scale of $z_{\Delta s}^{\prime}$. We thus define the statistic $\Im_{\Delta s}$ to quantify the scaling of the variation of the bed root-mean-square with $\Delta s[37]$

$$
\Im_{\Delta s}=z_{\Delta s}^{\prime} \sqrt{\Delta s} \sim(\Delta s)^{\vartheta}
$$

The scale at which $\Im_{\Delta s}$ deviates from the above power law relation represents the approximate maximum spatial window size at which the spatial correlation of the bed forms is maintained ([37]). In Figure 9 we apply this fluctuation analysis at the equilibrium state of bed form development (for this case after $t=1000 \mathrm{sec}$ ) and it is evident that the bed elevation fluctuations remain correlated up until $\Delta s \sim 0.7 \mathrm{~m}$. This coherence length scale of bed forms coincides with the average length of the measured and computed dune waves in the OSL (see Table 4). Bed forms of smaller length scale remain correlated and self-similar with a roughness exponent $\vartheta \sim 0.5$. This exponent is similar to that obtained by Escauriaza and Sotiropoulos [37], and Khosronejad and Sotiropoulos [64] for sand waves developing in the experimental open channel flumes with mobile sand beds.

Finally, in Figure 10 we plot the frequency spectrum of bed elevation on the OSL bed surface for a point along the centerline and at the center of OSL pool zone (the blue point indicated in Figure 1). As we show in Figure 10, for the low frequency range which corresponds to the larger and slowly migrating dunes, the spectrum exhibits -1 decay while for the higher frequency range, corresponding to smaller scale bed forms, the spectrum coincides with the $\sim-2$ power law relation. This rate of spectral decay for smallscale bed forms agrees with what has been observed before in laboratory experiments and numerical simulations [46, 37]. Using experimental data, Hino [46] showed that the frequency spectrum of bed forms has a power law relation with a decay of $f^{-2}$ for low frequencies near the peak of the spectrum, and argued that the -2 power law was mainly associated to the dynamics of ripples. Additionally, the numerical simulations of Escauriaza and Sotiropoulos [37], and Khosronejad and Sotiropoulos [64] obtained the same -1 and -2 slopes for the high and low frequency range of the spectrum, respectively, for developing sand waves. The recent experiments of Singh et al. [87] also showed the $\sim-2$ slope for bed forms in a large-scale, gravel-bed experimental flume. We noted that the reason our simulations cannot maintain the -2 spectrum at even higher frequencies is that the solution of the Exner-Polya equation in our model is based on a dissipative second-order scheme for the spatial derivatives, which, in the absence of a subgrid model for the fluctuations of the bed elevation, tends to smooth high-frequency features of the bed elevation.

\section{Simulation of dunes in large-scale meandering rivers}

In this section we demonstrate the ability of VSL3D to simulate the formation, growth, and migration of dunes in large-scale meandering rivers. We employ two river systems representative of large-scale gravel $(\mathrm{G})$ and sand $(\mathrm{S})$ rivers in nature and use them to construct two virtual channels within which bed form dynamics can be studied. The 
approach we employ to select these river systems is that developed by P. Diplas and coworkers and is described in detail in [89]. Here only a brief summary of this approach is provided. The representative river test-beds are selected using a combination of field data, hydraulic geometry regression equations, and one-dimensional hydraulic modeling with meander adjustments $[80,97,89]$. The field data set employed in this approach consists of 540 field points (450 for gravel bed rivers and 90 for sandy bed rivers)[78, 20]. Gravel and sand rivers are typically characterized by distinct ranges of hydraulic, sediment and geomorphological conditions. The combination of the various dimensionless parameters pertinent for each river type tends to result in different modes of evolution for gravel versus sand rivers. The range of relevant parameters for each river type is identified by statistically analyzing the data set and considering a range of published literature values. Based on this analysis along with one-dimensional numerical modeling to validate the selected slope, we select the parameter values for the representative $\mathrm{S}$ and $\mathrm{G}$ river test beds summarized in Table 6 . For both river systems we consider bankfull flow conditions identified using hydraulic geometry relations [80,97]. The reader is referred to [89] for more details of the overall approach.

Table 6: Characteristics of representative channels based on typical characteristics for sand and gravel rivers under bankfull flow conditions, including median grain size of bed material $d_{50}$, channel width $B$ flow discharge $Q$, mean flow depth $H$, bed slope $S_{o}$, sinuosity $s$, and wavelength of meander $\lambda_{m}$.

\begin{tabular}{lllllccl}
\hline River & $d_{50}(\mathrm{~cm})$ & $B(\mathrm{~m})$ & $Q\left(\mathrm{~m}^{3} / \mathrm{s}\right)$ & $H(\mathrm{~m})$ & $S_{o}$ & $s$ & $\lambda_{m}(\mathrm{~m})$ \\
\hline $\mathrm{G}$ & 3.2 & 27 & 36 & 0.9 & $3.2 \times 10^{-3}$ & 1.15 & 328.1 \\
$\mathrm{~S}$ & 0.5 & 27 & 48.4 & 1.35 & $7.0 \times 10^{-4}$ & 1.5 & 266.7 \\
\hline
\end{tabular}

The meander length of the representative sand $(\mathrm{S})$ and gravel $(\mathrm{G})$ rivers along their centerline is $266.9 \mathrm{~m}$ and $251.8 \mathrm{~m}$, respectively. We, in the subsequent sections, will numerically investigate the flow and sediment transport in three successive meander bends of each selected river. Each of the simulated S and G channels consists of three meander bends obtaining total length of $800.6 \mathrm{~m}$ and $755.5 \mathrm{~m}$, respectively.

\subsection{Computational details}

Simulations for both of these cases are carried out using the VSL3D in URANS mode along with the $k-\omega$ model for turbulence closure. This is because given the spatial scale of the two river systems we consider herein and the large temporal scales of bed evolution at such scale (of the order of several months), coupled hydro-morphodynamic LES, even coarsely resolved, is prohibitively expensive for the computational resources at our disposal. The simulations presented herein, however, provide the opportunity to demonstrate the ability of URANS model to capture bed form dynamics at large-scale, which, as discussed before, URANS failed to do at the OSL scale.

To demonstrate the ability of VSL3D to simulate bed forms at a large-scale with and without in-stream rock structures, we carry out simulations for the G channel with no structures and with the $\mathrm{S}$ channel with a single $\mathrm{J}$-hook vane installed at the meander apex along the outer bank. The background, structured curvilinear domain for each river system consists of three meander bends with vertical side walls and contains the sediment layer and the embedded J-hook vane structure for the S river case [89]. The side walls, sediment layer, and rock structures are meshed using unstructured triangular grids and 
Table 7: Computational parameters used for the $\mathrm{G}$ and $\mathrm{S}$ river test cases. $z^{+}$is the minimum near-wall grid spacing in wall units, $n_{s}$ and $n_{b}$ are the number of nodes used to discretized the unstructured triangular mesh at the sediment/water (live-bed surface) and structure/water (rock vane structure) interface, respectively, while $\Delta t$ and $\Delta t_{s}$ are the non-dimensional time steps for hydrodynamic and morphodynamic calculations, respectively.

\begin{tabular}{lllllll}
\hline Test case & $N_{x} \times N_{y} \times N_{z}$ & $z^{+}$ & $n_{s}$ & $n_{b}$ & $\Delta t$ & $\Delta t_{s}$ \\
\hline G river & $1201 \times 65 \times 29$ & 175 & 38752 & 106 & 0.01 & 1.0 \\
S river & $1321 \times 65 \times 29$ & 180 & 42859 & 112 & 0.01 & 1.0 \\
\hline
\end{tabular}

treated as immersed boundaries. The sizes of the computational grids for each case have been determined based on a grid size sensitivity analysis and are summarized in Table 7. It is important to mention that for the large-scale dune development simulations (test cases 4 and 5 below) presented in this section, we employ the quasi-synchronization dual time-stepping technique introduced in section 2.6. This approach is critical for practical simulations of bed morphodynamics at this scale since the underlying time-scales of dune migration is very long and the physical time that needs to be simulated in order to describe dune dynamics is of the order of several months. Using the quasi-synchronization approach [63], the non-dimensional time steps for flow field $(\Delta t)$ and morphodynamic $\left(\Delta t_{s}\right)$ computations were set equal to 0.01 and 1.0 , respectively. $\Delta t=0.01$ is chosen such that the maximum Courant-Friedrichs-Lewy (CFL) number is less than 1.0, while the larger non-dimensional time step for the morphodynamic computations $\left(\Delta t_{s}=1.0\right)$ is chosen such that the employed loose-coupling FSI approach to be numerically stable (for more details on the maximum stable $\Delta t_{s}$ see [63]).

For each test case in this section, we obtain the corresponding fully turbulent flow from a separate URANS calculation and prescribe it as inlet condition. The water free surface is assumed to be a rigid-lid boundary condition (for more details see [89]). At the downstream end of the domain, Newman outlet boundary conditions are employed for all three velocity components. At the solid side walls and mobile bed the wall functions approach is employed (for more details see [63]). The effective roughness height of the mobile bed and river side walls in the wall function is set to $d_{50}$ and $3 d_{50}$ for the gravel and sand bed rivers, respectively.

In order to emulate the natural condition of live-bed sediment transport in both rivers, we numerically recirculate the flow of sediment through the meandering rivers. This is accomplished by keeping track of the amount of sediment that exits the computational domain and re-introducing this amount at the next time-step at the inlet of the computational domain. The flow solver is first run over a rigid flat bed for several flow-through periods of time to produce initial flow field condition for the coupled simulations.

\subsection{The gravel $(G)$ river test case}

The simulation for this case continued for almost two months of physical time when the $3 \mathrm{D}$ dune waves are at their equilibrium state. The dynamic bed forms begin to appear after about simulating for 5 hours of physical time. The initially flat-bed river changes continuously as a series of bed forms migrate downstream with various celerities and interact with each other and the stream banks. In Figure 11 we show a snapshot of the computed instantaneous bed elevation at $t=50 \mathrm{hr}$. It is important to note that the 
depositional patterns observed along the meander inner bend in Figure 11 are strikingly similar with those observed in field photographs of large river systems (see Figure 12)[34].

The characteristics of the simulated dunes for this test case are plot in Figure 13, which show the contours of bed elevation during the first $100 \mathrm{hr}$ of the simulation in $s-t$ form. The horizontal axis $s$ in this figure is the arc length along the left bank of the G river, while the vertical axis $t$ measures time since the start of the coupled simulation. It is evident from Figure 13 that bed features of various sizes appear and evolve with time. As shown in Figure 13, the simulations start from a flat bed and the dune waves initiate after about $5 h r$.

In Figure 14 we show the simulated bed profiles along the left bank of the $\mathrm{G}$ river for the time intervals of $5 \mathrm{hr}$. The coupled simulation resolved the process of the dune waves formation, growth, and migration. As shown in Figures 13 and 14, the overall bed elevation near the outer bend and at the apex of the meander is lower than that of inner bend. The high and low bed elevations represents the locations of the scour hole and point bar near the outer and inner bend of the meander at the apex, respectively. The URANS model simulated dune waves are constantly present over the low and high bed elevation regions. The simulated dunes in this test case are found to have amplitude $\left(\Delta_{d}\right)$, wavelength $\left(\lambda_{d}\right)$, and average celerity that are in the range of $45-75 \mathrm{~cm}, 10-15 \mathrm{~m}$, and $1.1-$ $2.3 \mathrm{~m} /$ hour , respectively. We have compared these values with the field measurements data for large-scale natural rivers $[40,92,30,53,93,66,34,4,68,90,47,76]$ and the overall characteristics of the simulated bed forms fall well within the typical characteristic length scales of bed forms realized in nature and laboratory experiments. As an example, in Figure 15, we superimpose the simulated characteristic length scale (red points) of the captured bed forms as function of the effective bed shear stress, $\mathrm{T}$, in van Rijn's classical diagram (for more details see [93]). The red data points in Figure 15 represent the maximum and minimum size of the numerically captured dune waves of this test case.

\subsection{The sand $(S)$ river case}

For this test case, we simulated the coupled hydro- and morphodynamics for the $\mathrm{S}$ river with a J-hook vane structure installed at the apex of the meander bend. The presence of the embedded J-hook vane at a meander apex in the $\mathrm{S}$ river increases bed shear stress and turbulence intensities at the tip of the hook part and triggers the formation of a series of dune waves. The so initiated bed forms from the tip of the J-hook vane are seen in Figure 16 to continuously migrate downstream. The newly formed small dunes $\left(\Delta_{d} \sim 0.15 \mathrm{~m}\right.$ and $\left.\lambda_{d} \sim 4 m\right)$ at the tip of the J-hook migrate at higher celerity $(\sim 0.9 m /$ hour $)$ until they reach their maximum amplitude at about $100 \mathrm{~m}$ farther downstream (see Figure 16). At their maximum amplitude limit, the simulated dunes are as high as $\Delta_{d} \sim 1.5 \mathrm{~m}$ and as long as $\lambda_{d} \sim 30 \mathrm{~m}$ where they migrate with a celerity of $\sim 0.5 \mathrm{~m} /$ hour , which is roughly $50 \%$ slower than that of the small-scale dunes (see Figure 16).

The simulation period for this case is about two months of clock time during which we have also computed the maximum scour depth (at the outer bank near the apex location) and deposition height (at the inner bank near the apex location). For more detail on the scour depth calculations, the reader is referred to Sotiropoulos and Diplas [89]. As shown in Figure 16, despite of the migration and passage of large size dune waves that caused temporal variations in bed elevation along the river, the overall bed elevation near the outer bank of the $\mathrm{S}$ river is lower than the bed elevation at near the point bar (near the inner bend of the meander). 
The URANS simulated dune waves for this S channel with a J-hook vane tested against several field measured data for large-scale dunes in natural rivers [93, 90, 47, 76] and a reasonable agreement was obtained. As an example, in Figure 15 the numerically observed data points for this case are shown with blue points for the highest and smallest bed forms, which are well within the range of field data.

\section{Summary and conclusions}

We employed the VSL3D model with both URANS and LES approaches for carrying out coupled hydro-morphodynamic simulations of turbulent flow in different open channels, ranging from a stream to rivers, with mobile sand bed under live bed conditions with different configurations of commonly used in-stream rock structures. The numerical formulation introduced in the model can handle small to large size bed forms of arbitrary geometrical complexity, can account for stratified flow effects through the Boussinesq assumption, and can simulate both bed load and suspended sediment transport processes. By using a dual time-stepping technique incorporated in the VSL3D, we overcome the difficulty of dealing with the huge gap between the flow and morphodynamic time-scales and are able to simulate morphodynamic processes evolving over months of physical time. The VSL3D was applied to simulate the test cases studied experimentally in the SAFL OSL and two virtual meandering rivers in which we investigated dune wave initiation, growth and migration with sediment recirculation.

Spectral and statistical analysis of the calculated time series of bed elevations in the OSL demonstrate that the simulated medium size dune waves in the OSL exhibit scaling laws that are similar to those observed in experiments and in the field. Additionally, comparisons of simulated large-scale dunes, observed in the $\mathrm{G}$ and $\mathrm{S}$ rivers, with the field and other measured data showed that they are well within the expected range for the macro-scale dunes in the large rivers.

Use of the LES turbulence model coupled with the morphodynamic module is necessary to capture the intermediate-size bed forms in the OSL channel. At this scale the URANS model could only predict equilibrium scour and depositional patterns with good accuracy [63] but failed to capture the onset and rich dynamics of dunes. For the two largescale river systems the perturbations imposed by bed movement and the underlying flow structures are presumably sufficiently large for the URANS model to excite the bed instability and give rise to bed forms that are in good agreement with bed forms observed in nature. This is a major finding of this work as it clearly points to the ability of the VSL3D model to carry out practical engineering simulations of bed morphodyanmics at field scale. This finding also demonstrates the potential of the model to simulate the effect of flooding events on hydraulic structures and other infrastructure. An important feature of the model in this regard is shown to be the quasi-synchronized dual time stepping approach that is able to decouple the time scales of the flow and the bed evolution, thus, enabling efficient simulations of dune migration that occurs over several months of physical time.

A limitation of the morphodynamic model we have developed herein is that it is based on sediment entrainment and bed load flux relations that have been empirically correlated to the mean shear stress. In our work, as in previous studies [18, 37], we have assumed these correlations to be valid for instantaneous sediment and flow quantities. While there is no rigorous physical argument for supporting the validity of this assumption, 
the results we have obtained suggest that the proposed model can yield results that exhibit a great deal of physical realism. Models that can incorporate instantaneous flow quantities to calculate sediment entrainment have been proposed by Escauriaza and Sotiropoulos [38], who developed a transport equation for the sediment particle velocity within the bed load layer based on instantaneous forces acting on particles, and Coleman and Nikora [25, 26], who proposed a volumetric momentum balance approach. The hydromorphodynamic model we have developed herein presents a framework within which the performance of such models can be systematically evaluated both relative to each other and the empirical sediment transport relations we have incorporated in this paper. Such evaluation, however, needs to be accompanied by laboratory experiments able to resolve the effects of fluctuating flow forces on the motion of individual sediment particles (e.g. see [35]). As an improvement to the current level of modeling we did in this work, we intended to incorporate the effect of water free-surface on the flow field and bed form evolution using level-set method for calculating the free-surface [57]. This task can be carried out by simulating flow, free-surface, and morphology in a coupled manner. We also plan to systematically investigate in the future the effect of various modeling choices we have made in developing the VSL3D model. These include, for example, the selection of specific discretization schemes for the sediment transport equations and the effects of other subgrid scale models (for LES) and URANS turbulence models.

\section{Acknowledgments}

This work was supported by NSF Grants IIP-1318201, EAR-0120914 (as part of the National Center for Earth-Surface Dynamics) and EAR-0738726, and National Cooperative Highway Research Program Grant NCHRP-HR 24-33. Computational resources were provided by the University of Minnesota Supercomputing Institute. The field study to measure the bed form development at the SAFL OSL was supported by a Fellowship Award from National Research Council.

\section{References}

[1] M. Amsler, M. Blettler, I. de Drago, Influence of hydraulic conditions over dunes on the distribution of the benthic macroinvertebrates in a large sand bed river, Water Resour. Res. 45 (2009) W06426.

[2] B. Andreotti, P. Claudin, O. Devauchelle, O. Durn, A. Fourrire, Bedforms in a turbulent stream: ripples, chevrons and antidunes, Journal of Fluid Mechanics 690 (2012) 94-128.

[3] V.D. Angelis, P. Lombardi, S. Banerjee, Direct numerical simulation of turbulent flow over a wavy wall, Physics of Fluids 9 (1997) 2429.

[4] G.M. Ashley, Classification of large-scale subaqueous bedforms; a new look at an old problem, Journal of Sedimentary Research 60 (1990) 160-172.

[5] A.L. Barabsi, H.E. Stanley, Fractal Concepts in Surface Growth, Cambridge Univ. Press, Cambridge Univ. Press, New York., 1995.

[6] B.C. Barr, D. Slinn, T. Piero, K. Winters, Numerical simulation of turbulent, oscillatory flow over sand ripples, Journal of Geophysical Research 109 (2004) C09009, doi:10.1029/2002JC001709.

[7] J. Best, The fluid dynamics of river dunes: A review and some future research directions, Jouranl of Geophysics research 119 (2005) 1-21.

[8] P. Blondeaux, G. Vittori, Vorticity dynamics in an oscillatory flow over a rippled bed, Journal of Fluid Mechanics 226 (1991) 257-289.

[9] I. Borazjani, L. Ge, F. Sotiropoulos, Curvilinear immersed boundary method for simulating fluid structure interaction with complex 3D rigid bodies, Journal of Computational Physics 227 (2008) $7587-7620$. 
[10] D. Borg, I. Rutherfurd, M. Stewardson, The geomorphic and ecological effectiveness of habitat rehabilitation works: Continuous measurement of scour and fill around large logs in sand-bed streams, Geomorphology 89(1-2) (2007) 205-216.

[11] M. Cardenas, M. Gooseff, Comparison of hyporheic exchange under covered and uncovered channels based on linked surface and groundwater flow simulations, Water Resour. Res. 44(3) (2008) W03418.

[12] I. Celik, W. Rodi, Modeling suspended sediment transport in non-equilibrium situations, Journal of Hydraulic Eng 114(10) (1988) 1157-1191.

[13] Y.S. Chang, A. Scotti, Entrainment and suspension of sediments into a turbulent flow over ripples, Journal of Turbulence 4(19) (2003) 1-22.

[14] Y.S. Chang, A. Scotti, Modeling unsteady turbulent flows over ripples: Reynolds-averaged navierstokes equations (RANS) versus large-eddy simulation (LES), Journal of Geophysical Research 109 (2004) C09012, DOI:10.1029/2003JC002208.

[15] K.W. Chau, Y.W. Jiang, 3D numerical model for Pearl River estuary, Journal of hydraulic Engineering 127 (2001).

[16] L. Chau, K. Bhaganagar, Understanding turbulent flow over ripple-shaped random roughness in a channel, Physics of Fluids 24 (2012) 115102.

[17] Y.J. Chou, O.B. Fringer, Modeling dilute sediment suspension using large-eddy simulation with a dynamic mixed model, Phys. Fluids 20 (2008) 115103.

[18] Y.J. Chou, O.B. Fringer, A model for the simulation of coupled flow-bed form evolution in turbulent flows, Journal of Geophysical Research 115 (2010) C10041.

[19] A. Chrisohoides, F. Sotiropoulos, Experimental visualization of lagrangian coherent structures in aperiodic flows, Phys. Fluids 15 (2003) L25-28.

[20] M. Church, K. Rood, Catalogue of alluvial river regime data, Technical Report, University of British Columbia, 1983.

[21] L.B. Clarke, B.T. Werner, Synoptic imaging of nearshore bathymetric patterns, Journal of Geophysical Research 108(C1) (2003) 3005.

[22] G. Coco, B.A. Murray, G.M. O., Sorted bed forms as self-organized patterns: 1. model development, Journal of Geophysical Research 112 (2007) F03015.

[23] S.E. Coleman, J.D. Fenton, Potential-flow instability theory and alluvial stream bed forms, Journal of Fluid Mechanics 418 (2000) 101-117.

[24] S.E. Coleman, B.W. Melville, Bed form development, Journal of Hydraulic Engineeing 120 (1994) 544-560.

[25] S.E. Coleman, V.I. Nikora, A unifying framework for particle entrainment, Water Resour. Res. 44 (2008) W04415.

[26] S.E. Coleman, V.I. Nikora, Exner equation: A continuum approximation of a discrete granular system, Water Resour. Res. 45 (2009) W09421.

[27] S.E. Coleman, V.I. Nikora, S.R. McLean, T.M. Clunie, T. Schlicke, B.W. Melville, Equilibrium hydrodynamics concept for developing dunes, Phys. Fluids 18 (2006) 1051041-10510412.

[28] M. Colombini, A. Stocchino, Three-dimensional river bed forms, Journal of Fluid Mechanics 695 (2012) 63-80.

[29] R.M. Colombini, Revisiting the linear theory of sand dune formation, Journal of Fluid Mechanics 502 (2004) 116

[30] K.D. Crowley, Large-scale bed configurations (macroforms), platte river basin, colorado and nebraska: Primary structures and formative processes, Geological Society of America Bulletin 94 (1983) 117-133.

[31] K. D.A., K. D.E., Jacobian-free newton-krylov methods: a survey of approaches and applications, Journal of Computational Physics 193 (2004) 357-397.

[32] D. Derrick, Harland creek bendway weir/willow post bank stabilization demonstration project, in: Proceedings International Water Resources Engineering Conference, ASCE. San Antonio, TX.

[33] D. Derrick, Four years later, harland creek bendway weir/willow post bank stabilization demonstration project, in: Proceedings of 1998 International Water Resources Engineering Conference, ASCE. Memphis, TN.

[34] W. Dietrich, G. Day, G. Parker, Varieties of fluvial form, Varieties of fluvial form, John Wiley \& Sons Ltd, 1999.

[35] P. Diplas, C.L. Dancey, A.O. Celik, M. Valyrakis, K. Greer, T. Akar, The role of impulse on the initiation of particle movement under turbulent flow conditions, Science 322 (2008) 717-720.

[36] J. D.J., D. Mohrig, Formation of precambrian sediment ripples, Nature 433 (2005) 123-127.

[37] C. Escauriaza, F. Sotiropoulos, Initial stages of erosion and bed-form development in turbulent 
flow past a bridge pier, Journal of Geophysical Research 116 (2011) F03007.

[38] C. Escauriaza, F. Sotiropoulos, Lagrangian dynamics of bedload transport in turbulent junction flows, Journal of Fluid Mechanics 666 (2011) 36-76.

[39] J. Fredsoe, On the development of dunes in erodible channels, Journal of Fluid Mechanics 60 (1974) 1-16.

[40] J. Fredsoe, Shape and dimensions of stationary dunes in rivers, Journal of Hydraulic Division 108(HY8) (1982) 932-947.

[41] L. Ge, F. Sotiropoulos, A numerical method for solving the 3D unsteady incompressible navierstokes equations in curvilinear domains with complex immersed boundaries, Journal of Computational Physics 225 (2007) 1782-1809.

[42] M. Germano, U. Piomelli, P. Moin, W.H. Cabot, A dynamic subgrid-scale eddy viscosity model, Physics of Fluids A 3 (1991) 1760-1765.

[43] A. Gilmanov, F. Sotiropoulos, A hybrid cartesian/immersed boundary method for simulating flows with three-dimesional, geometrically complex, moving bodies, Journal of Computational Physics 207 (2005) 457.

[44] T. Hayashi, Formation of dunes and antidunes in open channels, Journal of Hydraulic Eng 96 (1970) 357-366

[45] D. Henn, R.I. Sykes, Large-eddy simulation of flow over wavy surfaces, Journal of Fluid Mechanics 383 (1999) 75.

[46] M. Hino, Equilibrium-range spectra of sand waves formed by flowing water, Journal of Fluid Mechanics 34 (1968) 565-573.

[47] R.R. Holmes, M. Garcia, Flow over bedforms in a large sand-bed river: A field investigation, Journal of Hydraulic Research 46(3) (2008) 322-333.

[48] S.C. Jain, J.F. Kennedy, The spectral evolution of sedimentary bed forms, Journal of Fluid Mechanics 63 (1974) 301-314.

[49] H. Jasaka, H. Weller, A. Gosman, High resolution nvd differencing scheme for arbitrarily unstructured meshes, Int. J. Numer. Meth. Fluids 31 (1999) 431-449.

[50] D. Jerolmack, Mohrig, Interactions between bed forms: Topography, turbulence and transport, Journal of Geophysical Research 110 (2005) F02014.

[51] D. Jerolmack, D. Mohrig, A unified model for subaqueous bedform dynamics, Water Resources Research 41 (2005) W12421.

[52] G. Jiang, C. Shu, Efficient implementation of weighted eno schemes, Journal of Computational Physics 126(1) (1996) 202-228.

[53] H. Johannesson, G. Parker, Proceedings: Flow field and bed topography in river meanders, in: National Conference on Hydraulic Engineering, ASCE.

[54] S. Kang, A. Lightbody, C. Hill, F. Sotiropoulos, High-resolution numerical simulation of turbulence in natural waterways, Advances in Water Resources 34(1) (2011) 98-113.

[55] S. Kang, F. Sotiropoulos, Flow phenomena and mechanisms in a field-scale experimental meandering channel with a pool-riffle sequence: Insights gained via numerical simulation, Journal of Geophysical Research 116 (2011) F0301.

[56] S. Kang, F. Sotiropoulos, Assessing the predictive capabilities of isotropic, eddy-viscosity reynoldsaveraged turbulence models in a natural-like meandering channel, Water Resour. Res. 48 (2012) W06505.

[57] S. Kang, F. Sotiropoulos, Numerical modeling of 3D turbulent free surface flow in natural waterways, Advances in Water Resources 40 (2012) $23-36$.

[58] J.F. Kennedy, The formation of sediment ripples, dunes and antidunes, Ann. Rev. Fluid Mech. 1 (1969) 147-168.

[59] A. Khosronejad, C. Hill, S. Kang, F. Sotiropoulos, Computational and experimental investigation of scour past laboratory models of stream restoration rock structures, Adv. Water Resour. 54 (2013) 191-207.

[60] A. Khosronejad, S. Kang, I. Borazjani, F. Sotiropoulos, Curvilinear immersed boundary method for simulating coupled flow and bed morphodynamic interactions due to sediment transport phenomena, Advances in Water Resources 34(7) (2011) 829-843.

[61] A. Khosronejad, S. Kang, F. Sotiropoulos, Experimental and computational investigation of local scour around bridge piers, Advances in Water Resources 37 (2012) 73-85.

[62] A. Khosronejad, J.L. Kozarek, C. Hill, F. Sotiropoulos, Simulation-based approach for stream restoration structure design: rock vanes, Journal of Hydraulic Engineeing Under review (2013).

[63] A. Khosronejad, J.L. Kozarek, F. Sotiropoulos, Simulation-based approach for stream restoration structure design: model development and validation, Journal of Hydraulic Engineering 140(7) 
(2014) 04014042.

[64] A. Khosronejad, F. Sotiropoulos, Numerical simulation of sand waves in a turbulent open channel flow, Journal of Fluid Mechanics (2014) 1-67.

[65] A.G. Kidanemariam, M. Uhlmann, Direct numerical simulation of pattern formation in subaqueous sediment, Journal of Fluid Mechanics 750 (2014) 1-13.

[66] R. Kostaschuk, P. Villard, Flow and sediment transport over large subaqueous dunes: Fraser river, canada, Sedimentology 43 (1996) 849-863.

[67] S. Kraft, Y. Wang, M. Oberlack, Large eddy simulation of sediment deformation in a turbulent flow by means of level-set method, Journal of Hydraulic Eng 137(11) (2011) 1394-1405.

[68] H.J. Lee, J.P. Syvitski, G. Parker, d. Orange, J. Locat, E. Hutton, J. Imran, Distinguishing sediment waves from slope failure deposits: field examples, including the humboldt slide, and modelling results. h. j. lee, j. p.m. syvitski, g. parker, d. orange, j. locat, e. w.h. hutton, and j. imran, marine geology, 192, 79-104, 2002., Marine Geology 192 (2002) 79-104.

[69] B.J. MacVicar, L. Parrott, A.G. Roy, A two-dimensional discrete particle model of gravel bed river systems, Journal of Geophysical Research 111 (2006) F03009.

[70] T. Matsuura, R. Townsend, Stream-barb installation for narrow channel bends-a laboratory study, Canadian Journal of Civil Engineering 31 (2004) 478-486.

[71] C. Matthaei, K. Peacock, C. Townsend, Scour and fill patterns in a new zealand stream and potential implications for invertebrate refugia, Freshwater Biology 42(1) (1999) 41-57.

[72] B. McElroy, D. Mohrig, Nature of deformation of sandy bed forms, Journal of Geophysical Research 114 (2009) F00A04.

[73] F. Mercier, S. Bonelli, F. Anselmet, P. Pinettes, J. Courivaud, J. Fry, On the numerical modeling of the jet erosion test, in: 6th Int. Conf. on Scour and Erosion, Paris, France.

[74] M. Nabi, H.J. de Vriend, E. Mosselman, J. Sloff, Y. Shimizu, Detailed simulation of morphodynamics: 3. ripples and dunes, Water Resources Research 49 (2013) W20457,.

[75] S. Niemann, J. Fredse, N. Jacobsen, Sand dunes in steady flow at low froude numbers: dune height evolution and flow resistance, Journal of Hydraulic Eng. 137(1) (2011) 5-14.

[76] J. Nittrouer, M. Allison, R. Campanella, Bedform transport rates for the lowermost mississippi river, Journal of Geophysical Research 113 (2008) F03004.

[77] NRCS, Stream Restoration Design, NEH 654, United States Department of Agriculture, National Resource Conservation Service, Washington, DC., 2007.

[78] W. Osterkamp, Gradient, discharge, and particle-size relations of alluvial channels in kansas, with observations on braiding, American Journal of Science 278 (1978) 1253-1268.

[79] C. Paola, V.R. Voller, A generalized exner equation for sediment mass balance, Jouranl of Geophysics research 110 (2005) F04014.

[80] G. Parker, P.R. Wilcock, C. Paola, W.E. Dietrich, J. Pitlick, Physical basis for quasi-universal relations describing bankfull hydraulic geometry of single-thread gravel bed rivers, J. Geophys. Res. 112 (2007) F04005.

[81] K.J. Ridchards, The formation of ripples and dunes on an erodible bed, Journal of Fluid Mechanics 99 (1980) 597618.

[82] J. Rominger, A. Lightbody, H. Nepf, Effects of added vegetation on sand bar stability and stream hydrodynamics, Journal of hydraulic Engineering 136(2) (2010) 994-1002.

[83] D.L. Rosgen, Cross-Vane, W-Weir, and J-Hook Vane Structures, Wildland Hydrology, Pagosa Springs, 2006

[84] A. Roulund, B.M. Sumer, J. Fredsoe, J. Michelsen, Numerical and experimental investigation of flow and scour around a circular pile, Journal of Fluid Mechanics 534 (2005) 351-401.

[85] P. Sagaut, Large Eddy Simulation for Incompressible Flows, Springer, Berlin, 1988.

[86] P.G. Scandura, G. Vittori, P. Blondeaux, Three-dimensional oscillatory flow over steep ripples, Journal of Fluid Mechanics 412 (2000) 335-378.

[87] A. Singh, P.A. F., F.G. E., On the influence of gravel bed dynamics on velocity power spectra, Water Resour. Res. 46 (2010) 1-10.

[88] J.S. Smagorinsky, General circulation experiments with the primitive equations, Monthly Weather Review 91 (1963) 99-164.

[89] F. Sotiropoulos, P. Diplas, Design methods for in-stream flow control structures, Technical Report, NCHRP Report (Project 24-33), Transportation Research Board, National Academies of Science, Washington, D.C., 2014.

[90] X. Tang, D. Knight, Sediment transport in river models with overbank flows, Journal of Hydraulic Engineeing 132(1) (2006) 77-86.

[91] S. Tjerry, J. Fredse, Calculation of dune morphology, Journal of Geophysical Research: Earth 
Surface 110(F4) (2005) F04013.

[92] L.C. Van Rijn, Sediment transport, part iii: Bed forms and alluvial roughness, Journal of Hydraulic Engineering 110(12) (1984 c) 1733-1754.

[93] L.C. Van Rijn, Principles of sediment transport in rivers, estuaries, and coastal seas, Aqua Publications, 1993.

[94] J.G. Venditti, M.A. Church, Bed form initiation from a flat sand bed, Journal of Geophysical Research 110 (2005) F01009.

[95] J.G. Venditti, M.A. Church, S.J. Bennett, On the transition between 2D and 3D dunes, Sedimentology 52 (2005) 1343-1359.

[96] D.C. Wilcox, Reassessment of the scale-determining equation for advanced turbulence models, AIAA Journal 26 (1988) 1299-1310.

[97] G.V. Wilkerson, P. G., Physical basis for quasi-universal relations describing bankfull hydraulic geometry for single-thread sand-bed rivers, Journal of Hydraulic Engineering 137(7) (2011) 739753.

[98] W. Wu, W. Rodi, T. Wenka, 3D numerical modeling of flow and sediment transport in open channels, Journal of Hydraulic Engineering 126(1) (2000) 4-15.

[99] M.S. Yalin, River Mechanics, Elsevier, New York, 1992.

[100] W. Yue, C.L. Lin, V.C. Patel, Coherent structures in open-channel flows over a fixed dune, Journal of Fluids Engineering 127 (2005) 858.

[101] E.A. Zedler, R.L. Street, Large-eddy simulation of sediment transport: Currents over ripples, Journal of Hydraulic Engineering 127(6) (2001) 444-452.

[102] E.A. Zedler, R.L. Street, Sediment transport over ripples in oscillatory flow, Journal of Hydraulic Engineeing 132(2) (2006) 1-14.

[103] L.Y. Zou, N.S. Liu, X.Y. Lu, An investigation of pulsating turbulent open channel flow by large eddy simulation, Computers\& Fluids 35 (2006) 74. 


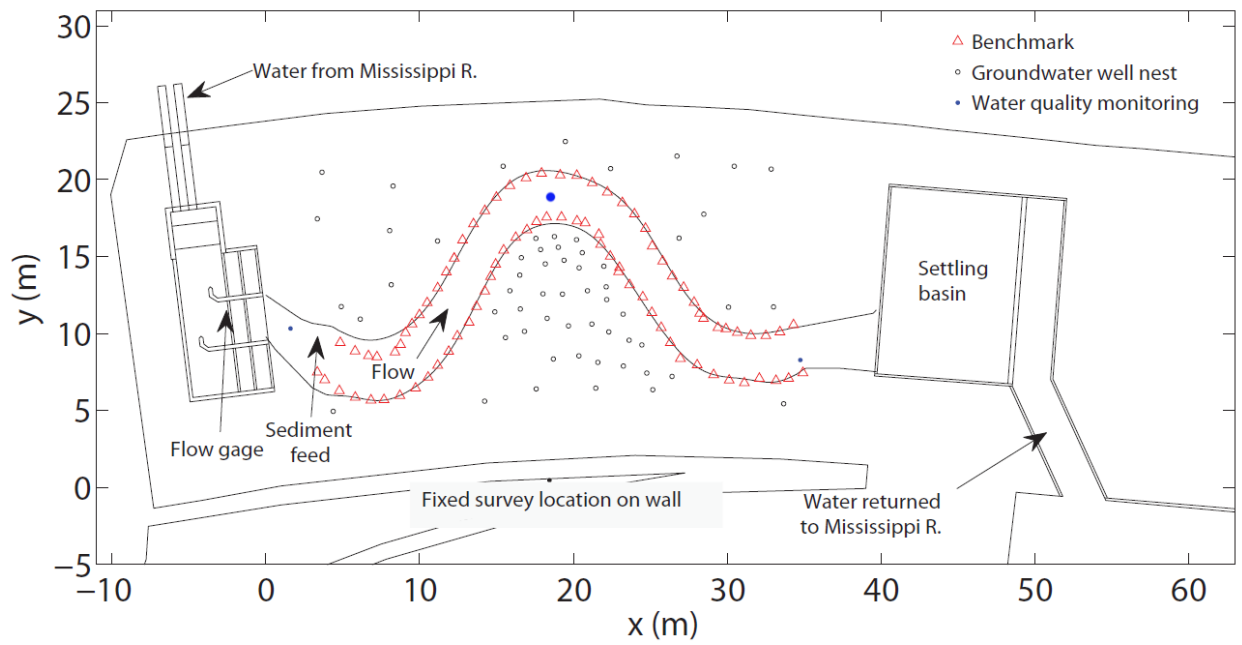

Figure 1: Schematic of the OSL channel illustrating the intake and settling basin layout from plan view. The blue point is located along the centerline and at the center of OSL pool zone. 


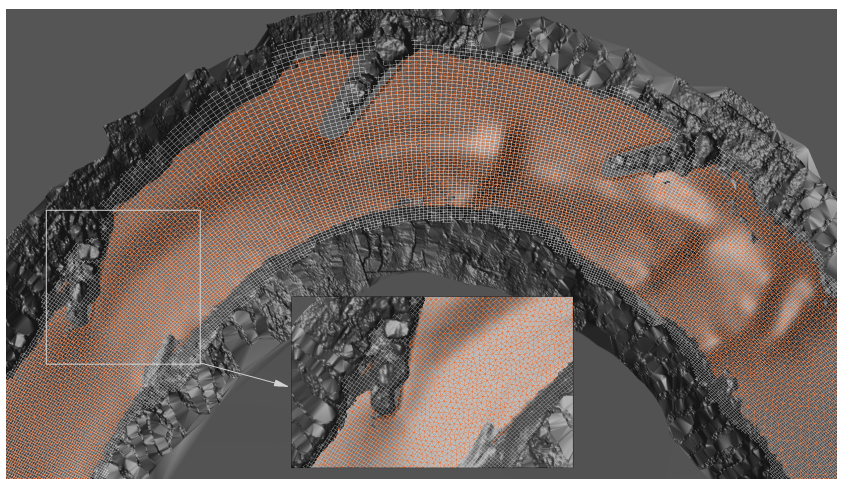

Figure 2: Schematic of the OSL approach employed in VSL3D to simulate flow and sediment transport in real-life streams with arbitrarily complex in-stream rock structures. The mobile bed (the gray layer on the bottom) is discretized with an unstructured triangular mesh (in orange) and treated as a sharpinterface immersed body embedded in the flow domain discretized with a structured curvilinear mesh (white lines). The stream banks and rock structures are discretized with a triangular unstructured mesh (the black gray rocks). The nodes of the structured curvilinear mesh located in the sediment layer (gray), banks (dark gray) and the rock structures (dark gray) are blanked out of the simulation. The average channel width, depth, and length in this figure are about $3,0.3$, and 18 meters. 


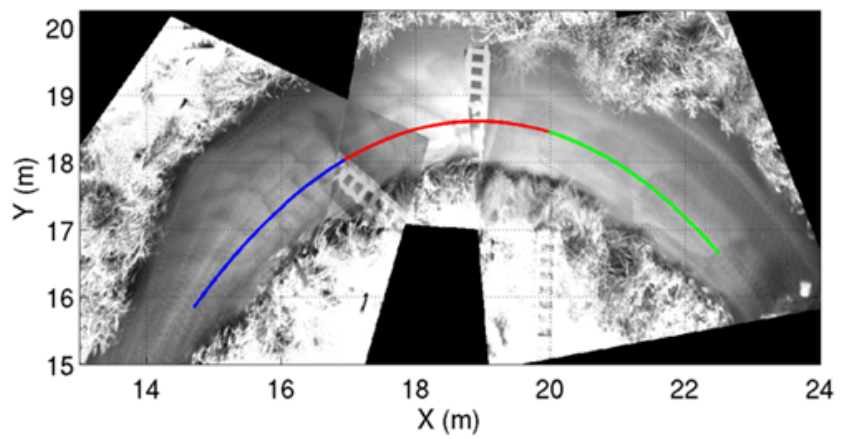

Figure 3: Plan view of the measured bed forms in the OSL channel with three distinct zones: blue (upstream of the apex), red (near the apex), and green (downstream of the apex). Flow is from left to right. 


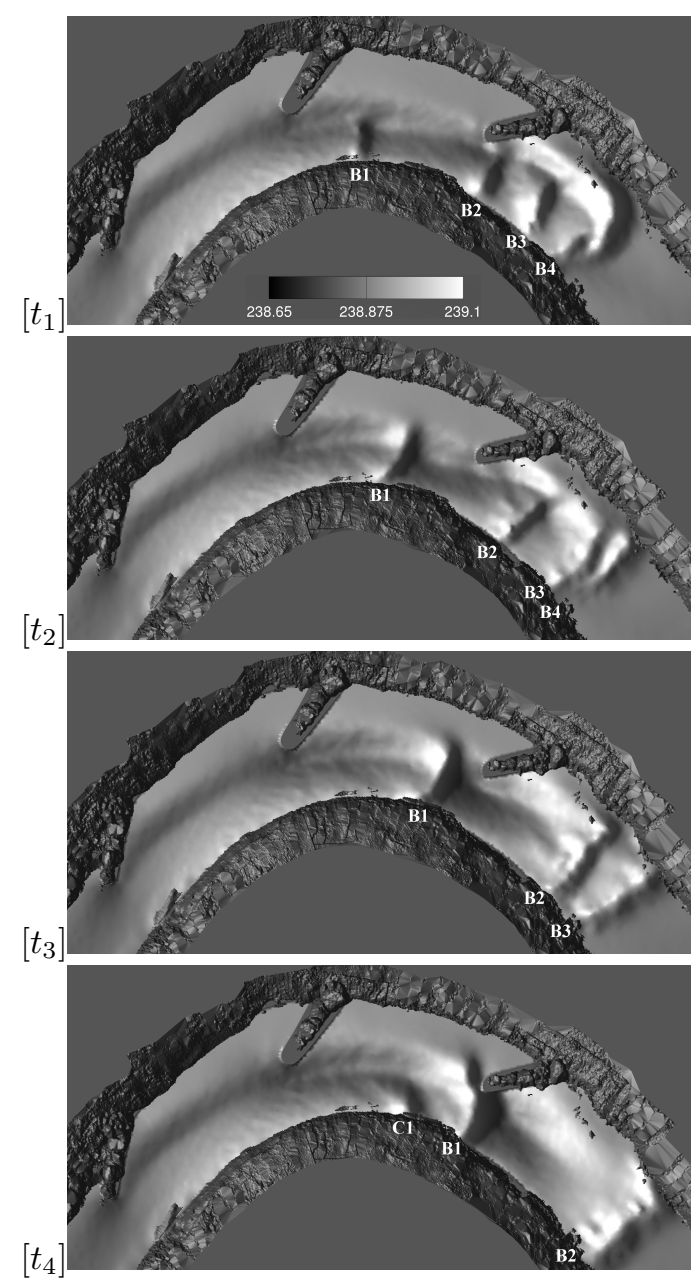

Figure 4: Computed bed forms in the OSL with three installed rock vane structures visualized with the instantaneous bed elevation contours at successive time intervals. Flow is from left to right. 

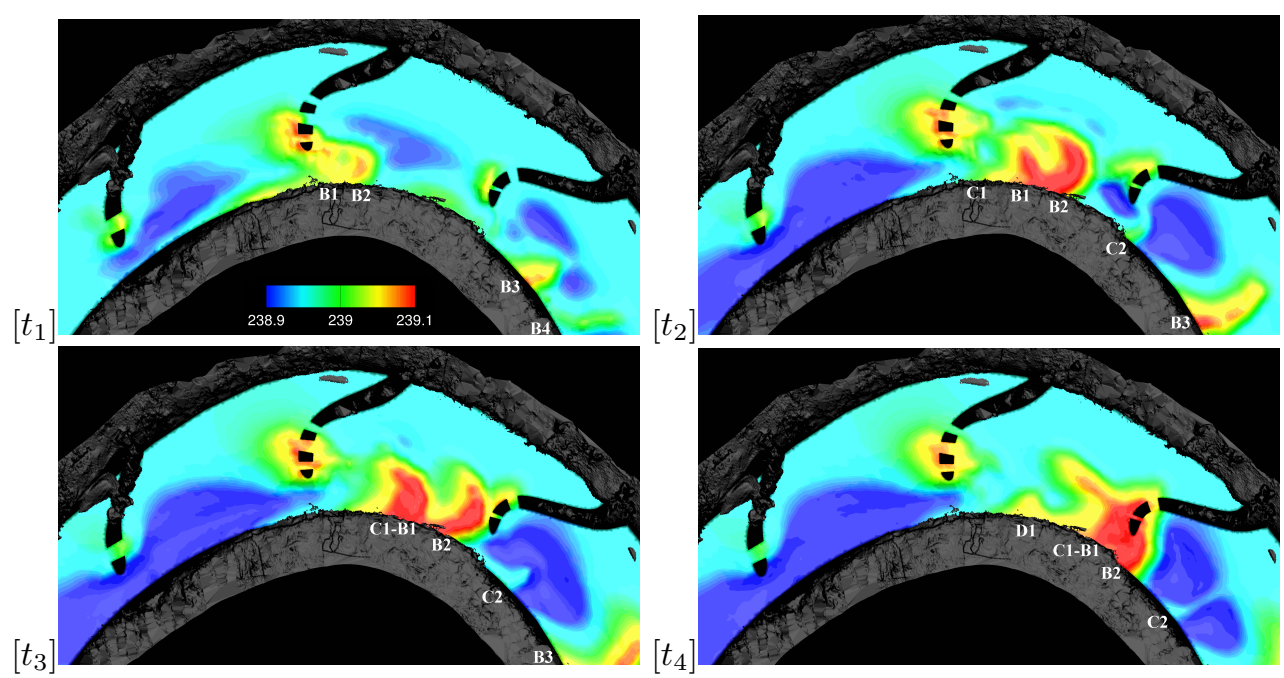

Figure 5: Computed bed forms in the OSL with three installed J-hook vane structures visualized with the instantaneous bed elevation contours at successive time intervals. Flow is from left to right. 


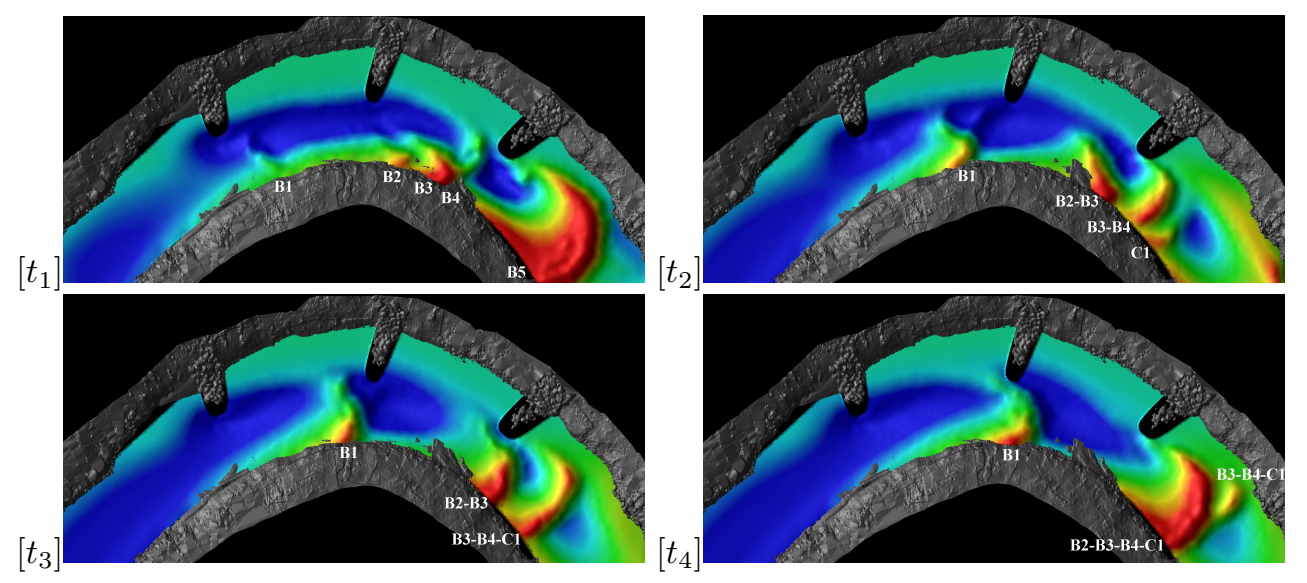

Figure 6: Computed bed forms in the OSL with three installed bendway weir structures visualized with the instantaneous bed elevation contours at successive time intervals. Flow is from left to right. 


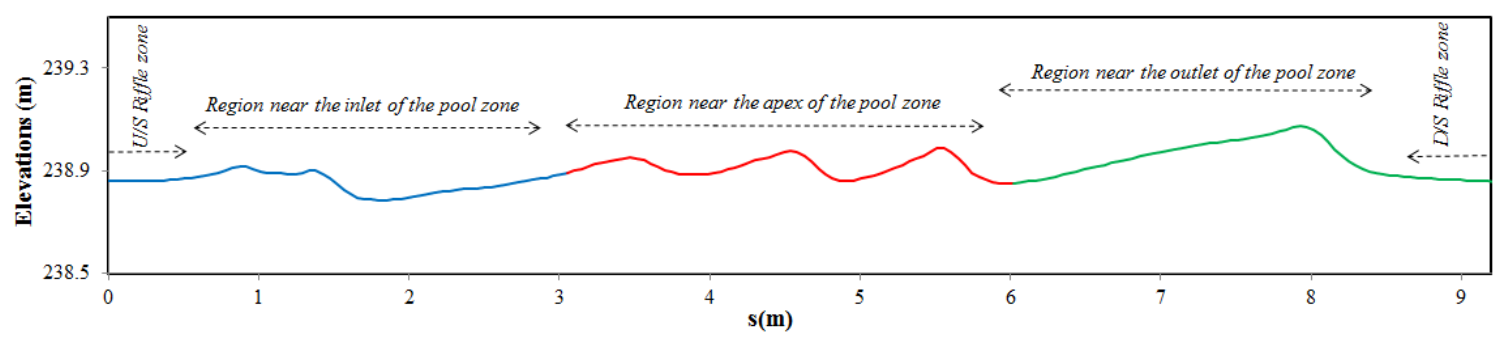

Figure 7: Instantaneous snapshot of simulated bed elevation profile along the centerline $s$ of the pool zone of the OSL channel for simulations in test case 3. The blue, red, and green zones show different stages of bed forms development, which corresponds to similar zones in the OSL experiment (see Figure $3)$. 


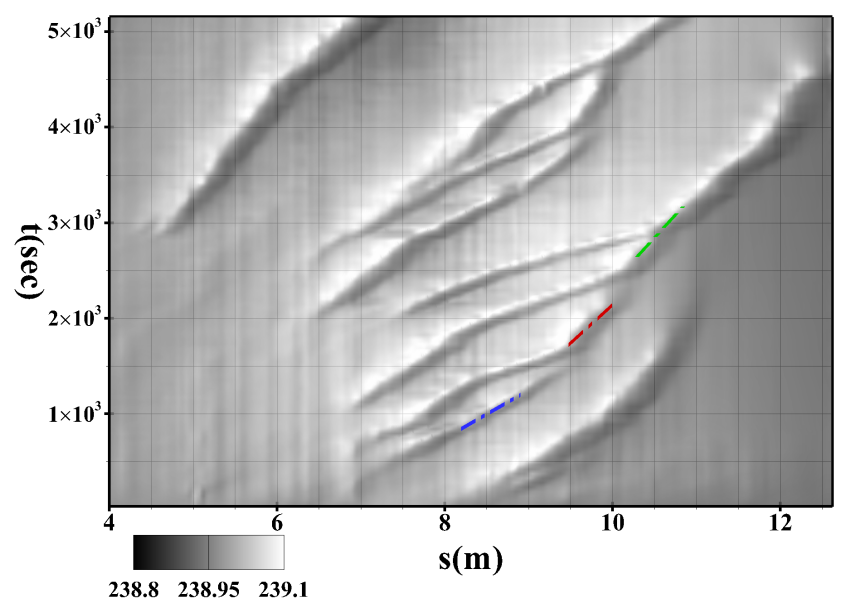

Figure 8: Computed contours of bed elevation $(m)$ in time along the $s$ coordinate showing the propagation of bed forms along the center line of the OSL for the representative case (test case 3). The dotted dashed blue, red, and green lines show the migrating velocity of dunes at different locations along the OSL channel. The milder slopes are associated with the higher waveform celerities. As shown, the small-scale and fast-traveling bed forms merge at farther downstream regions to form large-scale (up to $15 \mathrm{~cm}$ high) and slow-traveling dunes. 


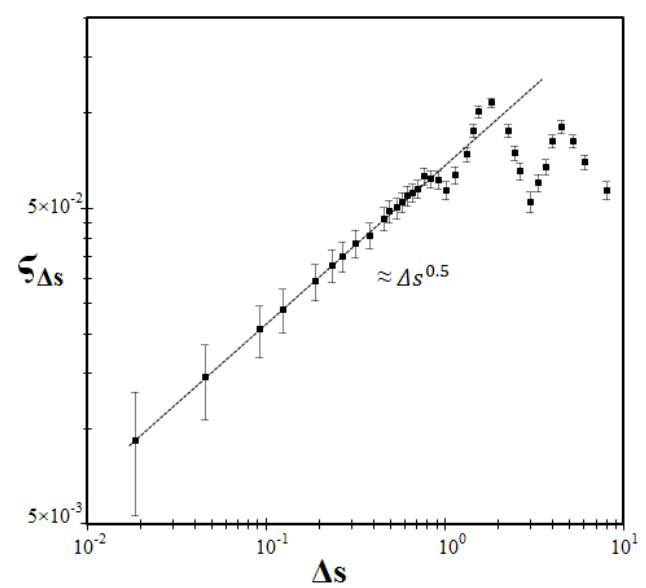

Figure 9: Statistics of computed bed elevation along centerline of the OSL that shows fluctuation diagram averaged over time. The error bars are associated with the standard deviation of $\Im_{\Delta s}$ and spatial window size $\Delta s$ is in meters.

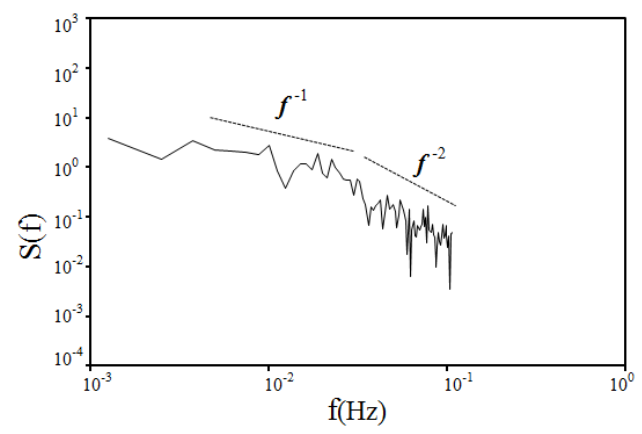

Figure 10: Frequency spectrum of computed bed elevation fluctuations at a point on the centerline of the OSL and in the middle of its pool zone. This point is also shown with a blue point in Figure 1.

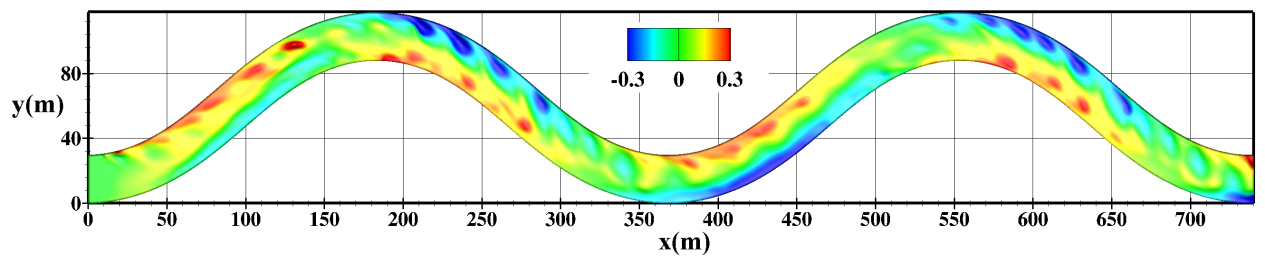

Figure 11: Color map of instantaneous bed elevation $(\mathrm{m})$ at $t=50 \mathrm{hr}$ showing the geometry of the simulated dune waves in the $\mathrm{G}$ river. Flow is from left to right. 


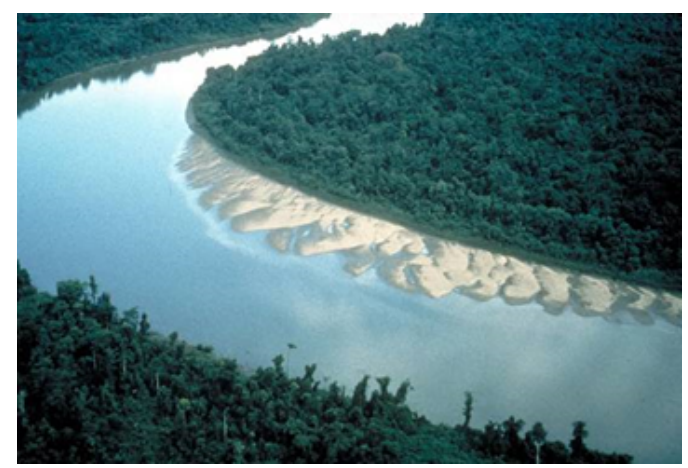

Figure 12: Field scale bed forms near the inner bend in a natural river [34]. Flow is from left to right.

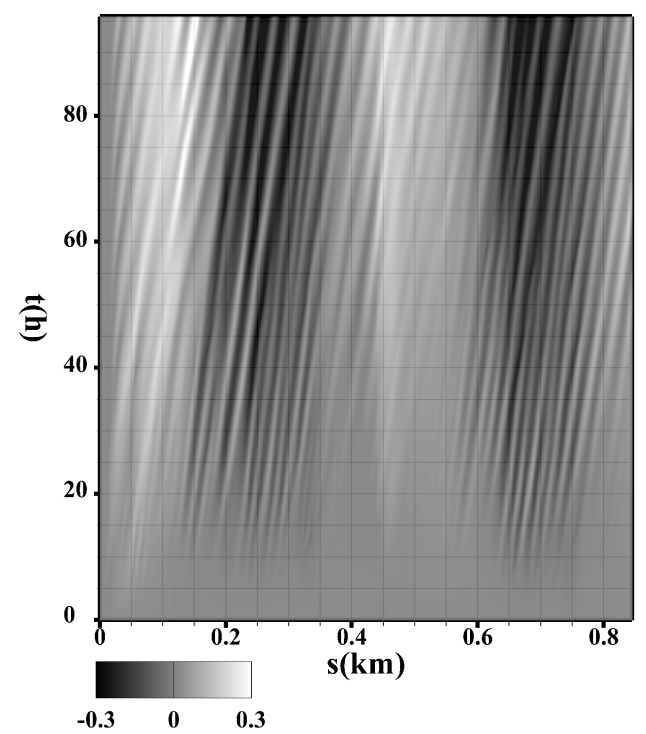

Figure 13: Computed contours of bed elevation $(m)$ in time along the $s$ coordinate showing the propagation of dunes along the left bank of the $\mathrm{G}$ river. 


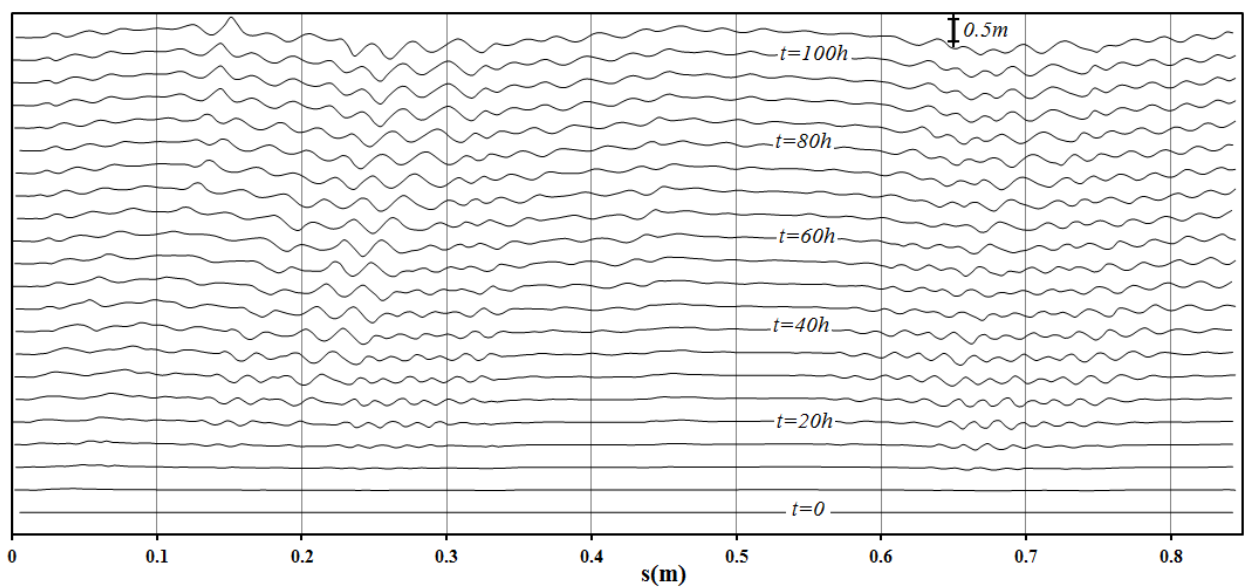

Figure 14: Computed bed elevation profiles along the left bank of the $\mathrm{G}$ river showing the migrating dune waves. The time interval of the bed profiles is $5 \mathrm{hr}$.

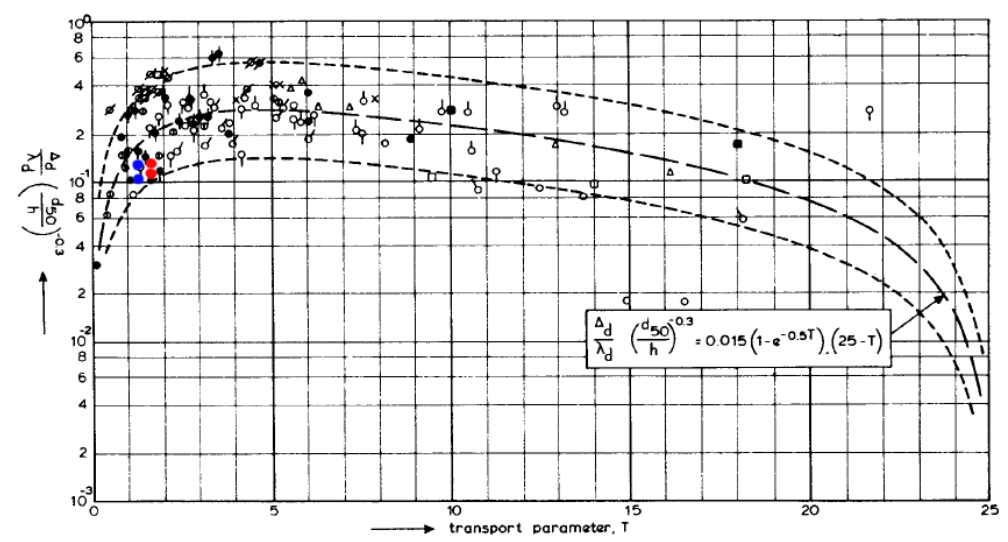

Figure 15: Characteristic length scale of the experimentally and field measured bed forms. The red and blue points represent the numerically captured dunes in the $\mathrm{G}$ and S rivers, respectively. 


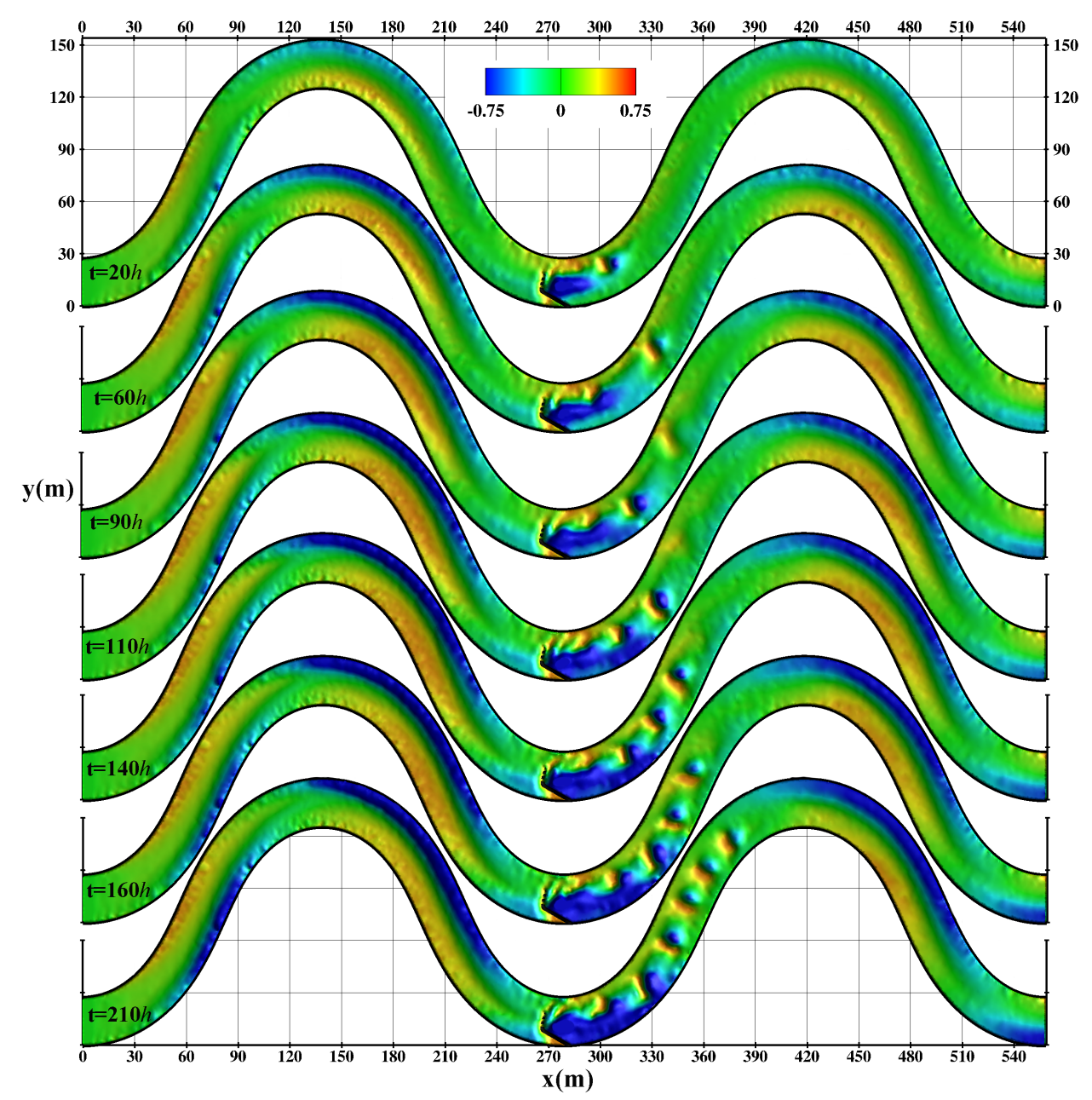

Figure 16: Color maps of instantaneous bed elevation (m) from time instant $t=20 \mathrm{hr}$ (top) to $t=210 \mathrm{hr}$ (bottom) showing the geometry of the simulated dune waves in the $\mathrm{S}$ river with a $30^{\circ} \mathrm{J}$-hook vane installed at the apex of the middle meander. Flow in all pictures is from left to right. 